\title{
Reference $\begin{gathered}\text { NBS } \\ \text { Pubili }\end{gathered}$ cations
}

\section{NBSIR 79-1937}

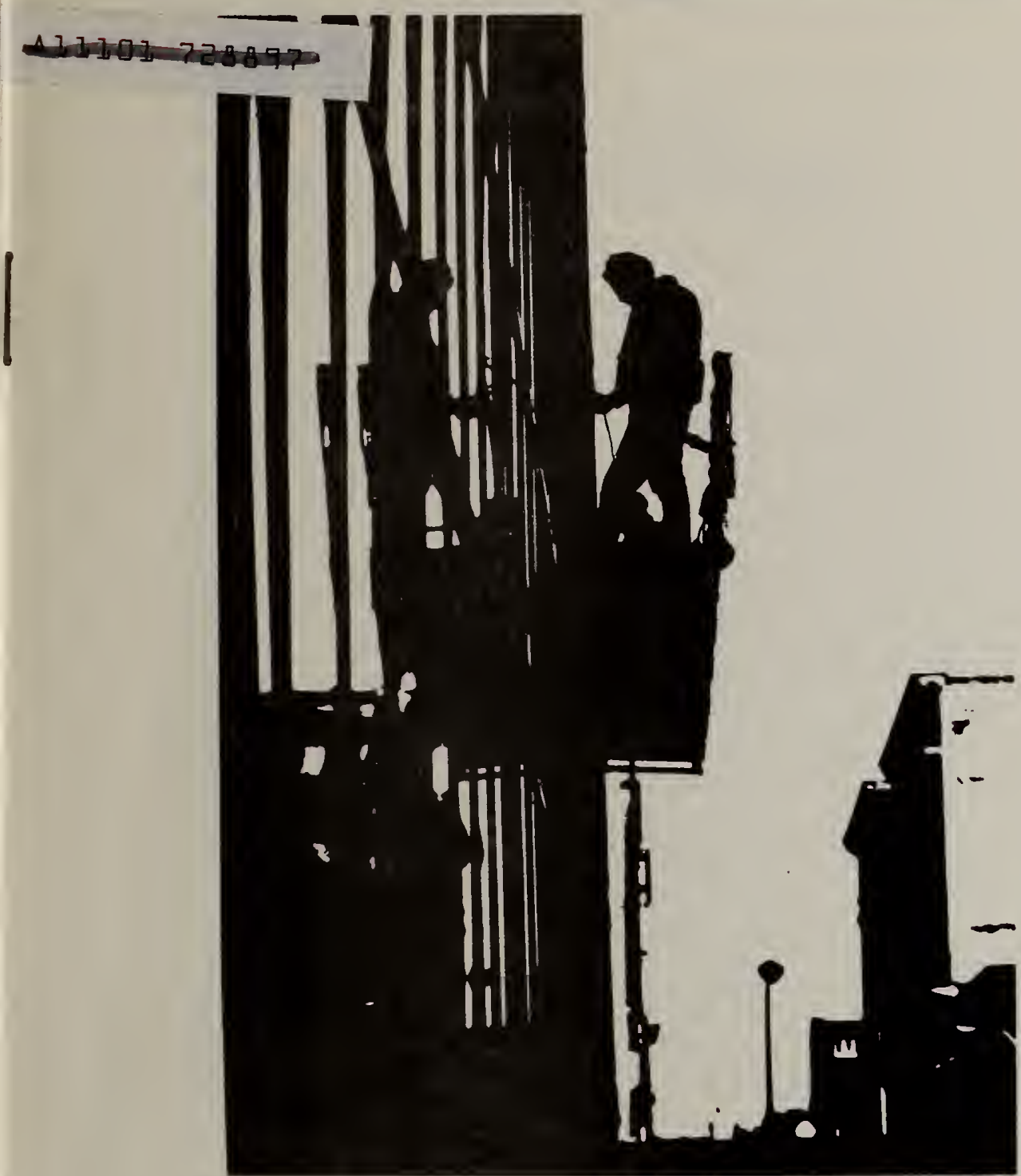

\section{Review of Current Codes and Standards for Scaffolds}

S. G. Fattal, C. L. Mullen, H. S. Lew, B. J. Hunt

Center for Building Technology

National Engineering Laboratory

National Bureau of Standards

Washington, D.C. 20234

April 1980

\section{$-Q C$}

100

.056

$79-1937$

1980

\section{Prepared for}

National Institute for Occupational Safety and Health

Department of Health, Education and Welfare

Washington, D.C. 

S. G. Fattal

C. L. Mullen

H. S. Lew

B. J. Hunt

Center for Building Technology

National Engineering Laboratory

National Bureau of Standards

Washington, D.C. 20234

April 1980

Prepared for

National Institute for Occupational Safety and Health

Department of Health, Education and Welfare

Washington, D.C.

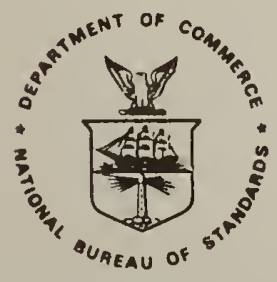

U.S. DEPARTMENT OF COMMERCE, Philip M. Klutznick, Secretary Luther H. Hodges, Jr., Deputy Secrotary Jordan J. Baruch, Assistant Secrotary for Scionce and Technology 



\title{
REVIEW OF CURRENT CODES \\ AND STANDARDS FOR SCAFFOLDS
}

\author{
S. G. Fattal, C. Mullen \\ H. S. Lew and B. J. Hunt
}

\begin{abstract}
$\underline{\text { ABSTRACT }}$
This report presents a critical review of the provisions in existing codes and standards for the design, erection, operation and maintenance of scaffolds used in construction work and other applications. The requirements in these documents were examined from the standpoint of clarity, consistency and completeness. Ambiguities arising from conflicting requirements or from provisions that led to more than one interpretation, and lack of consideration of major safety-related structural, environmental and human factors are highlighted. In addition, the adequacy of, and the rationale behind, the prescribed provisions are examined. These are supplemented by a specific application to wood platform design appearing in Appendix B. Appendix A illustrates common types of scaffolding systems that have been addressed by at least one of the codes or standards examined. The findings of this study serve to identify principal areas of needed research to improve present scaffolding practices.
\end{abstract}

Keywords: Codes and standards; construction safety; design; loads; maintenance; occupational hazards; scaffolds; stiffness; strength; structural safety; work surfaces. 


\section{ACKNOWLEDGMENTS}

This report was sponsored by the National Institute for Occupational Safety and Health (NIOSH), Department of Health, Education and Welfare. The authors wish to express their gratitude to those persons of the NBS staff, in particular Mr. Lou E. Cattaneo and Mr. Robert M. Eisenhard, whose efforts were of tremendous value in the compiling of this report. Also Dr. N. J. Carino for his untiring review efforts and Ms. Ana Sanchez and Ms. Ulesia B. Gray for the typing of this report. 


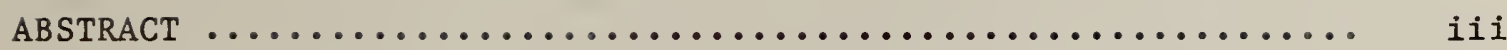

ACKNOWLEDGMENT $\ldots \ldots \ldots \ldots \ldots \ldots \ldots \ldots \ldots \ldots \ldots \ldots \ldots \ldots \ldots \ldots \ldots$ iv

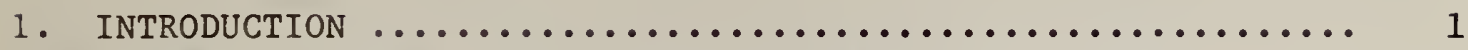

2. REVIEW OF GENERAL PROVISIONS FOR SCAFFOLDING SYSTEMS $\ldots . .$.

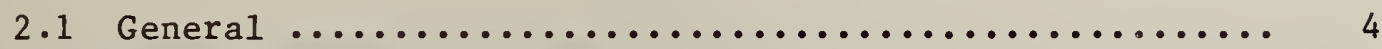

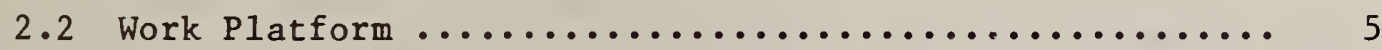

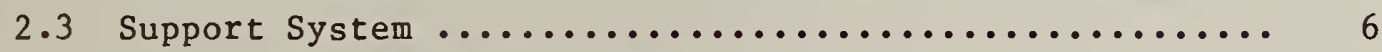

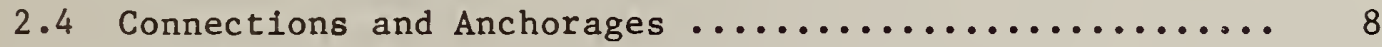

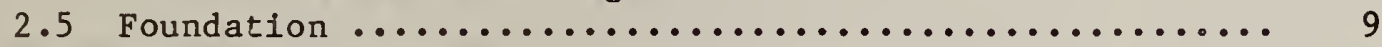

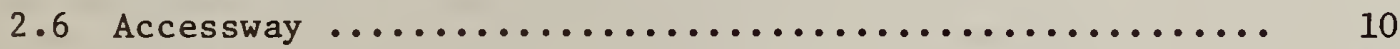

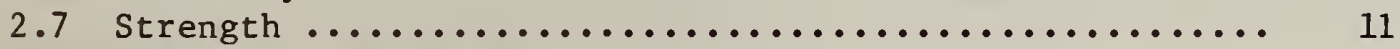

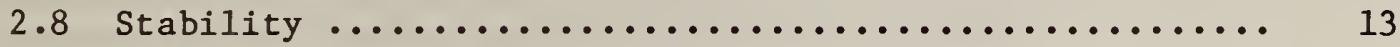

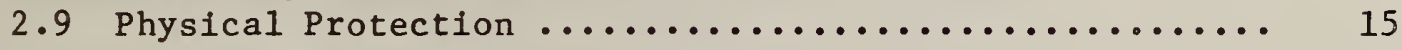

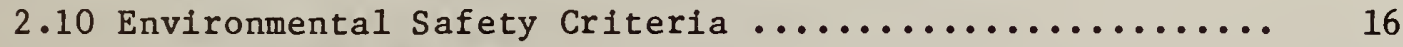

2.11 Special Provisions ......................... 17

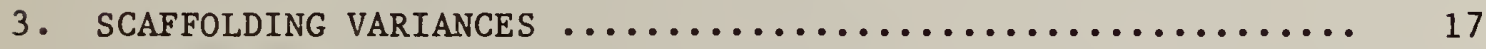

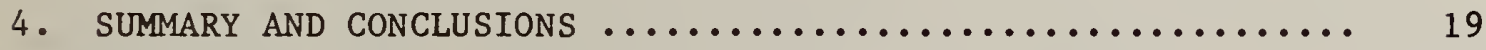

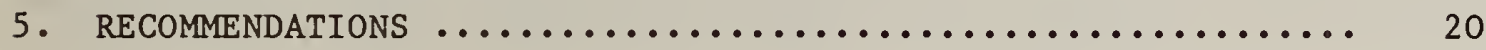

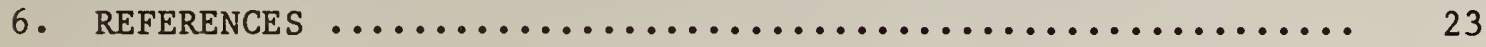

APPENDIX A - TYPICAL SCAFFOLDINGS SYSTEMS $\ldots \ldots \ldots \ldots \ldots \ldots \ldots \ldots \ldots$ A

APPENDIX B - APPLICATION SUMMARY AND REVIEW OF EXISTING STANDARDS FOR THE DESIGN OF WORK PLATFORMS CONSISTING OF WOOD PLANKING ............... B-1 



\section{INTRODUCTION}

At the present time, there exists no all-encompassing set of technically based criteria by which construction scaffclds can be evaluated for structural integrity, serviceability and personnel safety. In response to the need to minimize scaffolding accidents and consequent work-related human casualties, a research program has been initiated at the National Bureau of Standards (NBS) to develop the necessary technical basis for the improvement of current scaffolding provisions in existing codes and standards.

The scaffolding research program is organized into several phases consisting of a series of inter-related studies which may be identified by their subject matter as follows: Analysis of scaffold accident records and related casualties; review of scaffolding provisions of existing codes and standards; review and evaluation of existing technical literature on scaffolds; field study of scaffolding practices; analytical and experimental investigations; and development of performance standards for the design, erection, operation, maintenance and evaluation of construction scaffolds.

The initial phase of the scaffolding research program was sponsored by the National. Institute foccupational Safety and Health (NIOSH) and consisted of two separate studies. The first study, which dealt with the analysis of scaffolding accidents and related casualties, has been documented in a separate report [1].* The second study, which evaluates the scaffolding provisions of current codes and standards, is documented in this report.

A total of 25 codes and standards were initially examined for prescriptive content on safety requirements for scaffolds. This choice of documents represented a reasonable profile of scaffolding provisions in the U.S. and Canada. They consisted of four national codes, seven model codes and voluntary standards, five state codes and nine city codes. The number was narrowed down to eleven after eliminating those documents which either provided minimal or no coverage on the subject, or contained provisions similar to those in one of the retained documents. Nationally applicable documents retained for this study are the following:

(1) American National Standard, ANSI A10.8, A92.1, A92.2, A92.3, and 192.6 (ANSI)**[2].

(2) Occupational Safety and Health Standard, Part 1910 (OSHA 1910) [3]

* Numbers in brackets designate references listed at the end of this report.

** The terms in parentheses are abbreviations used for citing the corresponding documents in the text of this report. 
(3) Construction Safety and Health Regulations, Part 1926 (OSHA 1926) [4]

(4) State of California Construction Safety Orders (CAL/OSHA) [5]

(5) American Insurance Association National Building Code (NBC) [6]

(6) The Building Officials and Code Administration (BOCA) Basic Building Code [7]

(7) The National Research Council of Canada Construction Safety Code (NRCC) [8]

These documents were selected on the basis of the following considerations. The OSHA 1910 and OSHA 1926 documents are federally-enforced employee safety regulations applicable in the United States. The Occupational Safety and Health Administration (OSHA) exercises a mandate over all such regulations in accordance with the Occupational Safety and Health Act of 1970. The CAL/OSHA document is part of the State of California Administrative Code [9]. The CAL/OSHA employee safety regulations are applicable in the State of California by agreement with OSHA, and as such constitute an extension of OSHA employee safety jurisdiction to California. The ANSI document is a voluntary consensus standard which was used extensively as the basis for the development of the current OSHA regulations (OSHA 1910 and OSHA 1926). As a result, a marked similarity exists between these documents with regard to format, scope and technical content. The NBC Code is an enforceable document in the sense that 1 t prescribes safety requirements for insurability. The BOCA Code is widely adopted by state and local regulatory agencies, especially in the eastern parts of the U.S. A number of other nationally-referenced documents, such as the Uniform Bullding Code and the Southern Building Code, elther did not provide detailed requirements for scaffolds or did not reference other major codes or standards for such detalled requirements. The Canadian document was retained because it is the enforceable safety code in Canada.

In addition to national codes and standards, 13 state and city codes were examined. Of these, the following four were selected on the basis of the extent of specifics and detailed provisions for scaffolds contained therein:

(1) State of Connecticut Labor Department Construction Safety Code (Connect1cut) [10]

(2) The Wisconsin Administrative Code (W1sconsin) [11]

(3) C1ty of Atlanta Building Code (Atlanta) [12]

(4) City of New York Building Code (New York) [13]

The scaffolding safety requirements in the above documents were reviewed in terms of the following criteria: (1) comprehensiveness, (2) consistency, (3) clarity, (4) adequacy and (5) enforceability. A document is considered to be comprehensive if it contains those provisions that are deemed 
necessary for the maintenance of employee safety. Consistency refers to the absence of conflicting requirements. Clarity denotes absence of ambiguity such as statements which lead to more than one interpretation. Adequacy is judged according to whether a provision meets, exceeds or falls short of the intended level of safety. Enforceability is judged according to whether or not the user (designer, fabricator, contractor, inspector, compliance officials, etc.), to whom the requirement is addressed, can interpret and implement it in accordance with the intent of the code.

The following definitions are introduced to avoid possible ambiguities in the text of this paper when referring to parts and portions of the scaffolding systems.

Accessway

Anchor

Anchorage

Component

Connection

Element

Foundation

Platform

Safety devices

- physical devices installed for the protection of employees, such as guardrails, nets, belts, lanyards and lifelines, screens, etc.

\section{Structural}

system

Subsystem
- system which provides access of personnel to and from scaffolds

- component used for securing scaffold to foundation

- same as anchor, assembly of anchors

- unit used in the assembly of scaffolding system.

- component providing the means of attachment of other scaffolding components together.

- component or structural unit other than connection or anchor

- means providing total support to the scaffold system

- component(s) comprising the work surface of the scaffold

\section{- assembly of components serving a structural function}

- assembly of part of a system consisting of more than one element and one or more connections and/or anchors

Support element - element of scaffold subsystem which supports the platform and transmits applied loads to the foundation

System - assembly of components serving a specific function 


\section{REVIEW OF GENERAL PROVISIONS FOR SCAFFOLDING SYSTEMS}

\subsection{GENERAL}

Most of the documents reviewed are patterned after ANSI Al0.8. These documents are organized into general and type-specific provisions. The OSHA 1910 and OSHA 1926 documents closely maintain this organizational structure while CAL/OSHA and others adhere to ANSI A10.8 in varying degrees. The general provisions are those which apply to scaffolding systems of all types, while the type-specific provisions appear only under the heading of a particular type of scaffold.

Table 1 lists the types of scaffolds found in the ANSI (A10.8 and A92.X) and OSHA (1910, 1926 and CAL/OSHA) documents. Note that there is no complete agreement among these documents with regard to the terms used to describe specific scaffolding types, although in many instances they are the same. For example, it is difficult to discern whether Tower and Rolling Scaffolds of CAL/OSHA and Manually-Propelled Mobile Ladder Stands and Scaffolds of ANSI A92.1, OSHA 1910 and OSHA 1926, describe the same category of scaffold types. Another difficulty is that certain scaffold types appear only in some of the documents. A case in point is the Catenary Type which is addressed by ANSI 10.8 and CAL/OSHA but not by OSHA 1910 and OSHA 1926. Confusion is further compounded by the fact that many of the scaffolding types used by the construction and other industries do not belong to any of the specified categories. It should be noted, however, that these documents make provisions for conditions under which different scaffolding types could be used. ANSI A10.8 stipulates that exception may be granted by the enforcing authority to permit the use of other devices and methods when it is clearly indicated that equivalent protection is secured. The vehicle by which OSHA implements this provisions is to grant variances which are in effect only for a specific type of scaffold used for a specific job application. The mechanfsm by which variances are administered is discussed in section 3 .

Tables 2 a through $2 e$ provide a summary of the general scaffolding requirements contalned in the documents reviewed. For purposes of comparison, the provisions from the various sources are broken down into the following categories. It is noted that these categories do not exist within the documents reviewed per se, and that they are used only within the context of this report.

(1) Work platform

(2) Supporting elements

(3) Connections and anchorages

(4) Foundation

(5) Accessway

(6) Strength

(7) Stability

(8) Physical protection

(9) Environmental safety criteria

(10) Special provisions 
The first five items collectively identify basic components in terms of which all scaffolding systems can be defined. Strength and stability (items 6 and 7 ) relate to the structural safety of the system while item 9 refers to environmental safety considerations. In this respect, failure of any component of the system (items 1 through 5) could precipitate partial or complete collapse and therefore can be viewed from the standpoint of structural safety or stability (items 6 and 7). Similarly, items such as openings on the work platform or between the platform and the adjacent wall, various obstructions, etc. can be viewed as non-structural design factors or environmental factors affecting the safety of employees in the workplace. Physical protection devices (item 8 ) relate to both structural and environmental safety aspects. Under special provisions (item 10), situations requiring special consideration are listed (e.g. conditions under which the services of a professional engineer are required).

In most instances the type-specific provisions can be fitted into these categories as well. However, they are too numerous to be presented in tabular form. Instead, these will be cited at the appropriate places in the discussions of the general provisions in accordance with the specified format.

\subsection{WORK PLATFORM}

In many situations a work platform can be treated as a structurally independent element of the scaffolding system. Simply supported platforms or platforms continuous over more than two supports, for instance, can be analyzed for imposed loads by considering them separately from the system. Such an analysis then will provide information about the structural adequacy of the platform and can be used to set structural safety requirements.

Requirements listed in tables 2 a through $2 \mathrm{e}$ show that many specific provisions are prescribed for wood platforms by the various standards. Those of ANSI, OSHA 1910, OSHA 1926 and CAL/OSHA are essentially the same: a 2 in (50 mm) thick (nominal) scaffold grade plank is specified with maximum spans for loads of 25,50 and 75 psf $\left(1.2,2.4\right.$ and $\left.3.7 \mathrm{~N} / \mathrm{m}^{2}\right)$. For a summary and review of other provisions for the design of wood platforms, refer to Appendix B. Spans are also identified for use with planking having a minimum thickness of $11 / 2$ in $(38 \mathrm{~mm})$. However, no sizes are specified for loads exceeding the $75 \mathrm{psf}\left(3.7 \mathrm{~N} / \mathrm{m}^{2}\right)$ limit.

The approach which prescribes specific designs for platforms limits the scope of the standards. Similarly, the restrictive policy on acceptable lumber grades could create difficult situations in the event that the specified grades or species were to become scarce or unavailable. It should be noted that for certain types of scaffolds, OSHA permits the use of fabricated planking if it can safely support the specified load. There seems to be no apparent reason why such a clause should not be equally applicable to all scaffold types. In this respect, the Wisconsin Code uses a more general approach by requiring that safe loads be in 
proportion to the allowable stress and width of plank for a given span and that load distribution be considered in design. By emphasizing a design approach rather than prescribing a preconceived design, the provision is thereby rendered less restrictive with regard to choice of grade and plank size. The BOCA Code is likewise less restrictive in that it calls for the design of platforms to support specified levels of loading which are the same as those used by ANSI and OSHA. The rest of the State and local codes generally make reference to platform provisions in ANSI or BOCA.

Disparities are also found between the various standards and codes with regard to non-structural design requirements. ANSI allows a 1 in (25 mm) opening between adjacent planks while in most other codes no spacing is allowed. The Canadian Code requires platforms to be securely tied in place. In the New York City Code, a similar requirement is specified but only for "inclined planking", a term which is left undefined. On the other hand, ANSI and OSHA require platforms to be tied down or secured only for certain types of scaffolds (types 4, 8, 13, 21, appendix B). Generally, the required proximity of the scaffold to the face of the structure under construction is not adequately addressed.

\subsection{SUPPORT SYSTEM}

The term support system is used to designate the structure which provides direct support to the work platform and transmits all loads to the foundation. This could mean, for instance, a braced framework consisting of elements, connections and anchorages; a flexible or nonflexible (wire rope or bar) platform suspension system; a mobile or vehicle unit integrating a work platform; or any other system serving the defined support function. Appendix A illustrates various scaffold types and their support systems. The support system frequently identifies the characteristic feature of a scaffold and thereby constitutes the basis for making the distinction between the types appearing in Appendix A.

The provisions for support systems are primarily related to structural safety requirements for the individual elements, connections and anchorages to achleve a desired level of performance. In Table 2 "support systems" is not listed as a separate item because requirements for connections, anchorages, strength and stability can be treated more appropriately under separate headings. This section, therefore, dwells on provisions which affect the structural performance of the individual elements of the support systems.

Most of the provisions for support systems appear under type-specific headings for the various scaffolding configurations that are addressed. Because of the close similarity between the ANSI, OSHA 1910 and OSHA OSHA 1926 provisions for scaffolding support systems, it is convenient to address only one of these documents (OSHA 1926 is selected) and point out marked differences between $1 t$ and the other standards and codes examined. 
A potential structural safety problem for support systems is degradation of strength from repetitive use and exposure to the exterior environment. This is particularly true for systems which use wood elements in their construction. By referring to Appendix A, it is noted that at least 11 of the 21 scaffold types fall in this category. Degradation of wood manifests itself in the form of warping and bowing, decay, wear or cumulative construction damage (dents, cracks, delamination, nail perforations, etc.).

None of the documents reviewed contained definitive criteria to compensate for strength degradation of materials and components through such means as design modifications or repair and replacement of support elements. The extent of direct reference given to the topic by OSHA 1926 is a clause under the general provisions calling for the immediate repair or replacement of damaged and weakened parts. However, what constitutes damage that requires replacement is left to the judgement of the user. The CAL/OSHA Code calls for the inspection of scaffolding lumber before and at (unspecified) periods during use, and for replacement of pieces incapable of supporting 4 times the maximum imposed load. In many instances, there is no simple and practical set of rules to follow for determining compliance. Usually, verification is not feasible without an engineering analysis and/or some physical testing.

Similar inadequacies can also be found with regard to the lack of provisions for the repair, maintenance or replacement of support systems assembled wholly or partly from fabricated metal products. Noting that metal sections are relatively thin-walled, they would be more susceptible to physical damage or corrosion than wood. The type-specific requirements for metal support systems (such as types 2 through 7 , Appendix A) contained in ANSI and the other documents make no provision for the determination of strength loss due to these factors for the purpose of acceptance or rejection. The problem may be even more critical in the case of open metal sections in compression, such as diagonal steel angle braces that are often used in many scaffolding systems such as carpenter's brackets (type 16, Appendix A), because the stability of the entire system can be seriously impaired by the presence of bends, dents and other local damage.

In general, the problem related to the degradation of members such as noted above cannot be resolved without undertaking a comprehensive program to devise a practical approach (for instance, expedient field measurement and/or testing techniques) whereby the level of unacceptable damage can be established.

As in the case of platforms, the type-specific provisions for support systems appearing in OSHA 1926 (and most other codes as well) are limited in scope to specific prototype systems. In this respect, the provisions are similar to a set of instructions for assembling a commercial product. Even though this approach possibly simplifies the standard provisions for the layman, there are some obvious pitfalls. For example, under the Wood Pole category, the standard spells out sizes, lengths, 
projections and orientations of wood members to assemble a scaffold having a preconceived shape and layout. This inhibits the use of wood pole scaffolds having different framing arrangements, member sizes, allowable stresses, level and distribution of loads, etc., from those specified. It is true that in such cases variances may be granted by OSHA upon proof that the system provides "equivalent" protection. However, in a11 likelihood, the contractor will have to engage the services of an engineer to produce the required justification, in which case, a contradiction of sorts occurs because OSHA does not require the procurement of variances for engineered scaffolds in the first place.

Problems such as the above can be avoided by modifying the scope of the provision requiring engineered design so that it is equally applicable to systems not conforming with specific requirements in the standards. Another concept that might deserve consideration as a means of simplifying present OSHA scaffolding regulations and at the same time rendering them less restrictive for other systems, is to issue all specific designs under an appropriately titled separate reference (such as a Manual of Specific Scaffolding Systems and Practices Conforming with OSHA Regulations).

\subsection{CONNECTIONS AND ANCHORAGES}

Connections are components which fasten individual scaffolding components together to form the complete system. Any physical device used for the purpose of interconnecting support elements or braces, or securing work platforms, accessways or safety devices to the scaffold falls in this category. Common examples of scaffolding connections are nails and bolts for wood systems and pins, couplers and (shop) welds for metal systems.

In general, the codes and standards reviewed did not contain definitive provisions to ensure the integrity of scaffolding connections. ANSI A10.8 and OSHA 1910 call for the use of nails or bolts of adequate size and sufficient numbers to develop design strength (OSHA 1926 does not have specific provisions for connections). The obvious omission of quantitative criteria in this statement underscores the need for verification of strength through design or testing. The lack of a welldocumented design approach or a practical standard test method makes it difficult to exercise either of these options in a consistent and reliable manner. Furthermore, because the term "design strength" is neither explicitly defined nor a universally accepted term, it lends 1 tself to misinterpretation. If, for instance, it is taken to mean the allowable stress level of the incident elements at a joint, which incorporates a factor of safety, and the connection is proportioned using its ultimate capacity, the resulting design will not have the margin of safety to ensure connection integrity beyond working load levels.

A similar situation 18 encountered in an overall strength provision in both ANSI A10.8 and OSHA 1910 stating that scaffolds and their components shall be capable of supporting without failure at least four times the maximum intended load (see sec. 2.7). In this case, unlike connections, 
scaffolding elements are required explicitly to have a factor of safety of four. However, the terms "intended load" and "failure" are not clearly defined. If failure is associated with the load at which the element attains its peak resistance level, it should be so stated. Similarly, "intended load" needs classification because it could mean the "working load" anticipated by the design, or a recommended "working load" by the fabricator-supplier of system components directed to the erector and contractor to ensure that the system does not get overloaded under normal operating conditions.

Among the standards and codes reviewed, CAL/OSHA and the Wisconsin code address connections in greater detail than the other documents by specifying the quantity and type of fasteners and nails to be used in various applications. On the other hand, the Canadian Construction Safety Code is the only document that requires explicitly the connection strength be equal to the member strength. It further requires that the horizontal members shall not be spliced between two support points. This requirement provides against the possibility of premature failure of horizontal members which support the work platform.

Anchorages refer to those components which secure the scaffolding system to its foundation. Because anchorages provide either partial or total support to a scaffolding system, fallure of an anchorage could bring about a catastrophic collapse of the entire system. Except for a brief statement that scaffolds shall be secured to permanent structures, none of the standards and codes provided adequate coverage on anchorages. Furthermore, it is not clear whether a structure under construction can be classified as a permanent structure for anchoring purposes.

According to a recent study of scaffold-related accidents [1], a substantial portion of system failures were triggered by failures of anchors and connections. The present study suggests the possibility that the high rate of incidents involving such failures may be at least partially attributable to the absence of prescriptive technical provisions in the existing codes and standards applicable to the design of connections and anchorages. The source of the problem may be a lack of research information on the capacity of connections and anchors used for scaffolding applications. It is also possible that such information does exist but has not yet been fully utilized by the present codes and standards.

\subsection{FOUNDATION}

Foundation designates the total system which provides support to the scaffold. In this context, it may be the ground (footing or flooring) upon which the scaffold bears as well as any other supporting structure such as the partially completed wall of a building to which the scaffold is attached for lateral support. Connections between the scaffold and foundations are treated as anchorages (Section 2.4).

Referring to Tables 2 a through $2 \mathrm{e}$, a general lack of substantive provisions for scaffolding foundation is noted. The Canadian Code states that 
footings and supports shall carry the maximum load without unsafe settlement but fails to prescribe specific criteria by which a safe or unsafe settlement condition may be evaluated. The ANSI and OSHA documents state, in effect, that footings and anchorages be sound, rigid and capable of supporting the maximum intended load without settling or displacement. This is a requirement of several expected performance attributes without specifying the necessary criteria by which the level of performance can be established. In the absence of prescriptive criteria, the meaning of terms such as "sound" or "rigid" are subject to different interpretations by different users. In addition, the requirement that no displacement or settlement occur under loading is ambiguous in the sense that in a real-life situation loads always produce settlement and displacement. The ambiguity can be removed by restating the requirement so that settlements and displacements produced by the intended loads be kept within tolerable limits to provide adequate margins of safety against instability and structural distress.

Some of the type-specific provisions of ANSI and OSHA contain foundation clauses which use different wording but are otherwise just as ambiguous and void of prescriptive content as the general provision. For instance, under wood-pole scaffolds, OSHA 1926 states that poles shall bear on a foundation of sufficient size and strength to spread the load from the pole over a sufficient area to prevent settlement. This clause also appears almost identically in the Wisconsin Code. However, the latter does specify a footing size for wood scaffolds. This still leaves open questions with regard to the adequacy of the subgrade to safely support the specified footing irrespective of the type of soil, height of scaffold and anticipated loads.

It is also noted that none of the documents addresses the adequacy of the foundation when it consists of the partially completed or partially cured (in the case of concrete) part of a structure. There have been cases where the fallure of a partially cured foundation has precipitated collapse and high employee casualties. For example, the Willow Island Cooling tower collapse in West Virginia on April 27, 1978, which claimed the lives of 51 workers, may be viewed as an foundation fallure because of the inadequacy of the concrete shell (to which the scaffolding was attached) to resist the imposed construction loads without failure [14].

Since foundations have a direct bearing on both structural strength and stability (items 6 and 7 ), it is concluded that the present codes and standards do not contain adequate foundation provisions relating to scaffolding practices to insure structural safety in the work environment.

\subsection{ACCESSWAY}

Accessway refers to the means of access to and egress from the work platform. Except for two-point suspended scaffolds, most standards and codes call for ladder or other type access devices to the work surface. 
The Canadian code further requires that an accessway must be provided if the working platform is 1.7 meters ( $5 \mathrm{ft}$ ) above the ground or floor level while U.S. standards or codes have no such requirement. According to the accident study [1], injuries have occurred in the absence of access ladders as a result of workers jumping onto platform surfaces from higher elevations or workers falling while climbing on tubular metal scaffolds. Only a small percentage of accidents were attributed to failure of the accessway itself.

All the codes and standards reviewed fail to define accessway in terms of the above established criteria (i.e. comprehensiveness, consistency, clarity, adequacy, etc.). This situation occurs even under type-specific categories. Without the clear definition of accessway for all scaffolding types, the current provisions are incomplete, thus making enforceability impractical.

The standards and codes (OSHA 1910 and ANSI 10.8) cite the general requirement mentioned above that an access ladder or equivalent be provided to work platforms of all types. Under the type-specific category of tubular frame scaffolds (Type 3, Appendix A), only ANSI addresses a means by which access is to be provided. One such means is the attachable metal ladder which most manufacturers provide with this type of scaffold. However, the manufacturer also provides end frames, often titled 'step' or '1adder' type (Fig. A.5). These frames provide support for working platforms (which must extend beyond the support) as well as an indirect means of access.

To enhance safe practices of scaffolding uses, the codes and standards must clearly define the system components and address their function and use. The general trend indicates a worker using various system components for access to and egress from the scaffolding system. Horizontal elements, cross-bracing, platforms, platform rungs, etc., are typically used as accessways.

The codes and standards contain provisions on ladders, stairways, handrails, etc. (typical accessway components) under separate sections. By cross-referencing these existing provisions, the scaffolding requirements can be rendered more specific with regard to the use of proper accessways.

It is noted that there exist no accessway provisions for the expedient evacuation of personnel from well populated scaffolds in the event of disaster. Attention is drawn to we11-documented building code requirements for the evacuation of personnel in case of fire. These regulations can be used to model similar requirements for the safe evacuation of personnel from scaffold work platforms.

\subsection{STRENGTH}

ANSI Al0.8 and OSHA 1910 and 1926 contain a provision stating that "scaffolds and their components shall be capable of supporting without failure at least four times the maximum intended load". With the 
exceptions of the Wisconsin, Connecticut, and New York codes cited in Table 2, all of the other authorities reviewed contained a similar statement.

The above clause is so general that it appears to be an attempt to insure, in a single statement, that all scaffolds be sufficiently strong to protect people on or near the scaffold. Such a general statement is open to much criticism. No basis appears to have been given consideration in the selection of the value of four. Furthermore, interpretation and implementation are difficult and sometimes confusing. A recent technical review of OSHA regulations regarding scaffolding loads and actual margins of safety revealed major discrepancies [15]. Appendix B provides a summary and review of general provisions for strength in the design of work platforms consisting of wood planks and highlights problems inherent in interpreting the general requirements in terms of a factor of safety.

Safe design is primarily based on two major factors:

1. Adequate assessment of imposed loads, and

2. Provision of adequate resistance to imposed loads.

Without insight to actual loading configurations it is not possible to properly assess the safety of the design. It is important that the designers have at their disposal explicit guidelines of loads and loading ranges anticipated in service. In the case of scaffold design, such loads would include weights of the workers and materials, and equipment to be placed on the work platform. In addition, the effects of wind (lateral or uplift forces), falling objects (impact loads) or timevariation of loads (dynamic amplification) must be addressed. The ANSI reference to "maximum intended load" is open to numerous interpretations.

There exist two major design approaches used in determining the resistence of a structure. In the first approach, designers proportion components according to a specified allowable stress for the given material comprising the components. This approach is prescribed by steel and and wood design specifications $[16,17]$. In the second approach, the designer utilizes the ultimate* strength concept which represents a specific limit state. This approach is prescribed in the ACI concrete code $[18]$.

Under the working (or allowable) stress design, the service loads (or unfactored loads) are used in proportioning the structural members so that the working stress developed does not exceed the allowable stress for that given material. This specified allowable stress is determined by applying a code-specified factor of safety to the ultimate limit state of the

* Ultimate is a term which defines a peak or maximum characteristic for a specific material. 
material; the state at which a uniquely defined failure or unsatisfactory performance occurs (e.g., steel begins to yield).

Under the ultimate strength approach, the service loads imposed are increased by certain load factors to account for overloads for design purposes. The structural elements are then sized so that their expected capacities equal or exceed the factored design loads. In making the comparison between load and capacity, the theoretical capacities of the members are reduced by strength reduction factors to account for uncertainties in material properties and construction workmanship. The reason for these different approaches to structural design are manifold and are beyond the scope of this paper.

The ANSI statement of "support without failure" lacks clarity because failure of a structure can be defined in several ways. It can be defined in terms of the failure of either the system (global) or an element (local) that serves a load-carrying function. Excessive deflection or vibration may impair the proper conduct of work on the work platform to such a degree as to constitute failure. Furthermore, the inability to provide adequate strength margins against accidental abnormal loads, fire, or errors in fabrication or erection may contribute to failure. A review of statistical data in the accident study [1] provided evidence of failure of the latter type, particularly in regard to overloads and erection errors.

The above-mentioned design approaches must be consistent with specified definitions of failure modes. For a particular ultimate limit state, the problem that remains to be resolved is the significance of element failure or subsystem failure in relation to total collapse of the scaffold system. Considering a fabricated tubular frame scaffold (Type 3, Appendix A), for example, failure of a weld or a leg, or the absence of a brace may result only in local damage. Each constitutes failure according to an ultimate limit state. The accident study [1] indicated that the consequences of such local failures are usually not severe.

Different critical failure modes have different consequences. To establish a safety margin, the severity of the consequences should be considered. Either explicitly or by reference to other documents, all of the documents reviewed include a provision for a higher safety margin for suspension rope. The provisions call for support without failure of six times (vs. four times for erected scaffolds) the maximum intended load although the wording varied and was subject to different interpretations. Compared to erected scaffolds, the consequences of failure of a suspended system would be expected to be more severe because of a lack of built-in structural redundancies. This provides a logical explanation of the higher margin of safety prescribed for suspended systems.

\subsection{STABILITY}

The basic stability requirements for erected and suspended scaffolds are somewhat different. In erected scaffolds, where elements of the support system are in compression, structural instability or compressive buckling phenomena, at both local and global (system) levels, needs to be addressed 
in design. In suspended scaffolds, where the support elements (cables) are in tension, this type of instability is not a problem. Local structural instability, such as the buckling of a single compression strut, is usually confined to a small region, particularly when the system has built-in redundancies. On the other hand, global structural instability, such as out-of-plane buckling of a frame-type scaffold, often leads to total collapse. To ensure structural stability, bracing and lateral support requirements for the various systems will have to be determined either individually by design, or with the aid of tables and charts based on analysis.

Scaffolding systems must also be secured to prevent geometric instability such as rolling or overturning. This means that the scaffold must be anchored to its foundation in such a way as to inhibit rigid body displacements, and the foundation itself must be stable and capable of supporting the applied loads.

Lastly, "recoverable" displacements must be maintained within tolerable limits to ensure "stability" of working surfaces. This may be achieved by designing the structure for a required minimum stiffness and providing sufficient anchors to control excessive drift or vibration under certain types of loads such as wind and uplift. In the accident study [1], numerous casualties resulted from workers losing their balance because of excessive movements of the scaffold. Suspended scaffolds are particularly susceptible to this type of movement due to the inherent flexibility in the support system.

The codes and standards reviewed were found to be generally not cognizant of the types of stability problems noted above. The limited amount of information contained in these documents seldom meet the criteria of comprehensiveness, clarity, consistency, adequacy and thus enforceability. The type of statement such as "to prevent swaying or displacement" or "restrained from tippling by guying or other means", often encountered in these documents, is not accompanied by quantitative information by which the stability characteristics of scaffolding systems can be identified and controlled. The following ANSI Al0.8 provisions, which are frequently cross-referenced by other codes and standards (table 2) are cited as examples to illustrate the point.

ANSI required vertical structural elements to be "securely and rigidly braced to prevent swaying and displacement" and free standing towers with a helght-to-base ratio of 4 to 1 or more to be "restrained". The quoted terms, which can be interpreted in different ways, underscore the need to establish displacement tolerences by analyzing the effects of system component movements for the various scaffold types, configurations and loading conditions.

In a similar type of statement, support elements are required to bear on foundations of a size and strength capable of distributing the load safely. However, once again, criteria by which such a requirement can be met are not c1ted. 
Most of the documents require scaffolds to be "securely anchored" at specified horizontal and vertical intervals which vary according to the type of scaffold. Anchorage spacing requirement for the purpose of providing stability to the scaffold in the transverse direction will, in general, depend on the structural characteristics and spatial configuration of the system as well as on the magnitude and distribution of the applied loads. There is no indication that the effect of these factors have been considered in the development of the prescribed anchorage spacing requirements.

The effect of casters or wheels and locking devices on system stability must be studied as well. Criteria for locking devices under long-term repetitive use must be formulated because their performance is critical in maintaining the stability of mobile systems.

Another stability-related item is the use of cross bracing which is a requirement cited by all the documents. However, no specific guidelines are provided by which an adequate bracing system can be selected. A study by the Scaffolding and Shoring Institute [19] on tubular frame-type scaffolds indicates that the failure mode of the scaffolding assembly is characterized by out-of-plane buckling of the transverse frame units. This response is understandable in view of the high in-plane rigidity of the frame units coupled with the high flexibility and slenderness of the bracing elements. It would be of interest to study the effect of varying the frame-bracing stiffness ratio on the overall response of the system with the aim of developing criteria for optimizing the load response of the system. For instance, if the study shows that increasing the relative stiffness of the cross bracing elements produces a more favorable load distribution in the system and increases its ultimate load response, a revision of current practice to reflect this finding could lead to more economical designs and, at the same time, provide bracing elements which are less susceptible to accidental damage.

\subsection{PHYSICAL PROTECTION}

Most of the documents contain specific requirements for protective devices such as guardrails, safety belts, screens, etc., and, in addition, specify where and under what conditions they shall be used. However, there are some fundamental environmental safety-related differences in the prescribed values which cannot be logically explained. For example, where guardrail use is specified, ANSI, OSHA 1910 and OSHA 1926 require that they be installed on open sides and ends of all platforms higher than $10 \mathrm{ft}(3.1 \mathrm{~m})$ above ground, while according to CAL/OSHA, the corresponding figure is $7.5 \mathrm{ft}(2.3 \mathrm{~m})$.

OSHA 1926, additionally requires that on a scaffold having a minimum width less than 45 in $(1.1 \mathrm{~m})$, guardrails be installed at platform heights greater than $4 \mathrm{ft}(1.2 \mathrm{~m})$ above ground. This height is also a requirement of the Canadian Code, but the stated reason is not minimum width but rather the presence of wheel barrows and other vehicles on the platform. Lastly, the Atlanta Code contains the somewhat ambiguous requirement that guardrails be installed on platforms greater than $20 \mathrm{ft}$ above ground 
or $6 \mathrm{ft}$ above floor level. Similar discrepancies can be found when considering the various code provisions on the use of safety belts and lifelines as indicated in tables 2 a through $2 e$. The OSHA documents are not altogether clear whether the lifeline should be independently supported or wether the employee is required to "wear" it during the conduct of work.

The issue of major concern from the standpoint of employee safety, is the height of platform above which protective safety devices should be made mandatory. Insight into the problem was gained by analyzing the existing accident records involving falls of employees from heights and related consequent injury and death statistics. It is difficult to reconcile with the implication that if an employee falls from an unprotected work platform just under $10 \mathrm{ft}(3.1 \mathrm{~m})$ high, the likelihood of serious injury or death is such that the absence of guardrail or other protection will constitute an acceptable level of risk by one standard but not by another.

Finally, a point of somewhat less concern, but nonetheless one that makes the present OSHA documents unnecessarily voluminous, less readable, and confusing is the duplication of text on the provisions for guardrails and other safety devices. In OSHA 1926, for instance, specific guardrail provisions are first stated under the general heading, and repeated, almost identically, 15 different times under various type-specific headings. It will take only minimal modification to consolidate under general provisions a substantial amount of repetitive text on safety devices that now appear under the type-specific headings, and thereby render the osHA regulation more concise and effective.

\subsection{ENVIRONMENTAL SAFETY CRITERIA}

With the exceptions of the Wisconsin and Connecticut codes, all codes and standards reviewed contain at least one or two provisions relating to safety of the work environment. These provisions deal with five sources of environmental hazards: objects falling from above, the natural environment (wind, snow, ice), clutter or protruding objects, corrosive substances, and fire. The accident study [1] corroborates the existence of these hazards. Usually these conditions cause the worker to lose his balance. The consequences of the loss of balance varied, depending on the support system, from a critical fall to a bruised leg. Injury from a falling object or a protruding nail can be serious, depending on which part of the body is contacted and the magnitude of force applied by the object striking the person.

The ANSI and OSHA documents offer the most comprehensive coverage of the environmental hazards mentioned. ANSI calls for overhead protection where needed, treatment of rope (suspension cable or lifeline) in the presence of corrosive substances, and protection of rope or other members in the presence of heat-producing processes. It prohibits workers from working on scaffolds during storms or high winds, or working on platforms covered with ice and snow unless they are removed and the planking sanded. It prohibits tools, materials, or debris, from accumulating on platforms 
and the use of corrosive substances unless approved by the manufacturer. OSHA adds to these a provision for the use of wire ropes when acid solutions are used for cleaning buildings which are higher than $50 \mathrm{ft}(15.2 \mathrm{~m})$.

The model codes cited in table $2 c$ ( $N B C$ and BOCA) have fewer provisions on the conditions under which fire protection is needed as well as on type and level of protection that should be provided. NBC limits the maximum height of overhead protection to $10 \mathrm{ft}(3.1 \mathrm{~m})$ above the platform. NRCC includes provisions for protection against splinters and protruding nails.

CAL/OSHA has provisions similar to ANSI but excludes the item of fire protection. Permission is granted for some reason for workers to access platforms with slippery conaitions if these conditions are a necesary part of the work. The other state authorities cited in table $2 \mathrm{f}$ (Wisconsin and Connecticut) do not have any provisions for environmental safety.

The environmental provisions in the New York and Atlanta Building Codes are few and focus on combustibility of materials, a hazard which none of the other codes address. The scaffold accident study [1], however, provided evidence that such a hazard exist and may lead to serious injury or death.

\subsection{SPECIAL PROVISIONS}

This section addresses situations requiring special attention and consideration by the scaffold designer or user. These situations are grouped under the category of Special Provisions in table 2. Many of the special provisions call for engineering services when unique design conditions occur that are not addressed specifically. In most instances, the special provisions are general in nature; however, clarification of numerous items is needed if deviations by the user are to be prevented.

Under the category of 'general' in ANSI, exceptions are permitted to the literal requirements if granted by the enforcing authority, if equivalent protection is provided. Where the various types of scaffolds are provided with more than one working level, the existing provisions require that professional services be used for their design. For clarity, such requirements should be factored out from the type-specific provisions and categorized as special provisions under the general heading.

\section{SCAFFOLDING VARIANCES}

The possibility exists that some situations in the field are deviations from the OSHA scaffolding requirements but are nct actual infractions. The application for, and authorization of variances, and other relief from occupational safety and health standards and regulations are discussed in CFR Title 29 (Labor) 1905.10. A brief discussion of OSHA variances is given below together with examples abstracted from cases documented in the Occupational Safety and Health Reporter published by the Bureau of National Affairs, Inc. (BNA).

When considering the many types of scaffolding used, both in general industrial occupations (1910.28) and in construction activities (192.6 
451), the OSHA regulations set forth numerous general and specific requirements. The purpose of enforcing these scaffolding requirements is, of course, to reduce hazards to personnel in various occupations. However, there have been instances in which none of the scaffold types, supplied and used as required (i.e., in compliance with the OSHA Scaffolding Regulations), were suited to accomplish the job at hand satisfactorily. In some of these cases, the employing companies have required and have been granted permission to bypass the regulations by using a specially designed scaffold or by introducing some non-complying modification. Such variances, nevertheless, usually include the addition of other compensating requirements intended to offer the employee equivalent safety under the working conditions of the particular job for which the variance is granted. For example, additional requirements might be imposed for the posting of danger warning signs or of maximum load limits. It is important to note that the granting of the variance applies only to the requesting company for the situation described and not to other companies even though they might have the same working conditions with which to contend. Some illustrative situations for which OSHA variances have been granted, follow:

case 1:

The applicant was engaged in chimney construction and maintenance and stated that in constructing a chimney, the elevated platform or scaffolding is moved upward with the construction. As the height of construction reaches $122 \mathrm{~m}$ (400 ft) or more, it becomes impractical to use an access ladder [OSHA 1926.552 (c) requires the construction of hoist towers when hoisting personnel]. The applicants claimed that there was insufficient room on the small chimneys to build a hoist tower.

For these and additional claims of difficult conditions, the company was authorized (1) to transport personnel to and from the elevated platform on chimneys under construction using a special workmen's hoist in lieu of complying with 1926.552 (c) and (2) to transport personnel one at a time, to and from an elevated scaffold on small diameter chimneys under construction; or from a bracket scaffold outside the chimney using a boatswain's chair (in place of the material bucket) attached to a material hoist bucket, with the worker's safety belt attached to a safety clamp and lifeline according to the authorized instructions. These variations were allowed provided additional conditions were met regarding the construction and the operation of the hoist.

case 2:

The applicants were involved in constructing tanks made of steel plates consisting of ring segments. This activity required special scaffolding which is highly portable and is raised up the shell of the tank as new steel plate ring segments are added. If 1926.451 (a) (4) were compiled with (guardrail supports not to exceed $8 \mathrm{ft}(2.4 \mathrm{~m})$, and table $\mathrm{L}-3$ were followed (1926.451 (a) (10) - maximum allowable planking span), it would be necessary to attach brackets to the ring plates at $7.8 \mathrm{ft}(2.4 \mathrm{~m})$ intervals. A spacing of $10.5 \mathrm{ft}(3.2 \mathrm{~m})$ was required for the plates 
which were $31.4 \mathrm{ft}(9.6 \mathrm{~m})$ long. In addition, the tank scaffolds do not have toe boards as required by 1926.451 (a) (4) (5), and there were some guardrail discrepancies caused by the goemetric difference between the curved face of the tank and the straight adjacent edge of the scaffold platform which led to the use of taut wire rope as a safety line.

Consideration of the applicants' claim resulted in their being authorized to use the special scaffolds provided that: (1) loose tools were kept in well-designed containers secured to prevent their upset; (2) areas beneath working zones were roped off and posted with warning signs; and ( 3 ) additional precautionary measures were taken regarding scaffold occupancy and assemblage.

Because variance is granted only to one applicant (or a group of applicants involved in a given operation), similar requests and decisions are to be found documented for different applicants. Since the frequency of requests for a particular variance may have some influence on recommendations for future modifications of scaffolding requirements, a more detailed examination of documented scaffolding variances should be performed.

\section{SUMMARY AND CONCLUSIONS}

'this report presents a review and assessment of scaffolding safety provisions in existing codes and standards. The documents examined are voluntary consensus standards and mandatory codes and regulations under Federal. state and local jurisdictions. The study is part of an NBS research project to develop the technical basis for the improvement of current scaffolding practices.

The review places emphasis on the structural and environmental aspects of safety. For the purpose of comparison, each document is broken down into ten categories and each category is examined separately in the text. Table 2 presents a summary of the various provisions under the appropriate categories. Appendix A illustrates 21 specific types of scaffolds addressed by the codes and standards. Appendix B discusses the technical basis used in the design of wood platforms and highlights differences between it and the scaffolding regulations.

The findings of this study bring into focus critical deficiencies in the present scaffolding provisions. A prevalent trend is the inclusion of requirements for compliance with certain expected performance attributes without giving any specifics by which the level of performance can be judged. Most notable is the absence of definitive criteria for the design or evaluation of the adequacy of anchorages, connections and foundations. It is significant that the failure of these same components were found to be the leading causes of scaffolding accidents according to an earlier study [1].

For work platforms and the support system, the provisions tend to be generally more specific, sometimes to the extent of recommending actual scaffolding systems. This latter approach, however, tends to inhibit 
the use of alternative schemes which provide equivalent protection, unless permission is granted through the variance process in the case of OSHA Construction Safety Regulations.

For load supporting elements, most of the documents have adopted a simplified approach by recommending a factor of safety of 4 against failure. However, in many instances, this approach is not consistent with present materials-oriented codes and standards which taken into consideration strength as well as ductility and other structural response characteristics of the product in developing the prescribed safety margins.

Some of the documents reviewed prescribed quantitative requirements related to system stability, such as the provision of longltudinal and transverse bracing and spacing of anchorages. However, it is judged that these requirements will have to be supplemented by additional requirements, such as strength-based criteria for determining sizes of bracing elements, sizes and embedment lengths of anchorages, and displacement tolerances of supports, before they can adequately cover for the stability of scaffolding used in construction practice.

In general, the documents examined do provide for the protection of personnel from environmental hazards by prescribing requirements for keeping working surfaces free of debris, clutter, ice, sharp projections and unguarded openings, and for the installation and use of safety devices. There are cases, however, where the required level of protection against a specific environmental hazard varies from one document to another, and not all documents address the same set of environmental hazards.

Deficiences are also noted with regard to the lack of definitive guidelines for the evaluation of strength and stiffness degradation in service, or provision of appropriate criteria for the repair, maintenance and replacement of damaged components.

\section{RECOMMENDATIONS}

Based on the review of existing scaffolding provisons presented in this report as well as an analysis of scaffolding accidents documented in a separate report [1], the following areas of research are recommended:

1) Conduct a comprehensive review of the technical literature regarding the scaffolding topics outlined in this paper.

2) Conduct a field study to identify scaffolding designs, loads, specific applications and practices.

3) Develop a technical research plan by which construction scaffolding can be analyzed, and implement this plan so that necessary data can be obtained for further analytical use.

4) In accordance with the technical basis estalished above, develop improved criteria for the design and evaluation of scaffolding systems used in construction work. 
A review of technical literature serves two important functions. It identifies pertinent research data that can be translated into criteria for adoption by codes and standards. It also identifies areas of needed research where technical information is scarce or unavailable. Based on the findings documented in this report, the study of technical literature should concentrate on the following items:

- Identify technical research information on anchors and connections used in scaffolding applications. Topics of major concern are the strength characteristics of nails, fasteners, bolts, clamps, couplers, and anchoring devices.

- Review current literature regarding structural testing and evaluation of scaffolding system and their components, including fabricators' data.

- Identify existing evaluative techniques to assess bearing and displacement characteristics of foundation materials and their suitability to support scaffolding structures at grade level. Identify literature on transfer of stress from thin-walled tubes across end bearing configurations.

- Review the literature on movement, instability and displacement limitations of scaffolding systems, and the effects of such movements on human sub jects.

- Review the technical basis by which safety and physical protection devices were developed, and criteria for their application to scaffolding systems,

- Review technical literature on impact and dynamic effects on scaffolding systems and their components.

In conjunction with the literature search, it is recommended that a concurrent field survey be performed, to gather pertinent information on the practical aspects of scaffolding applications for use in the later analytical portion of the study. Recommended areas of specific interest are the following:

- Collect information on the range and distribution of construction loads according to type of construction and type of scaffold. This information is mandatory for the analytical research phase.

- Assess support system degradation and maintenance conditions and practices, especially weathering effects on lumber and corrosion effects on steel.

- Identify prevalent types of anchors and connections with emphasis on material type and application. 
- Identify types and configurations of foundations and relate them to type and size of scaffold used.

- Identify types of accessways in conjunction with the various types of scaffolding uses.

- Assess susceptibility of system components to accidental damage which might lead to instability problems.

- Identify environmental conditions regarding clutter, protrusions, exposure of workers to falling objects, fire, corrosion, etc.

The literature and field study information will be used to develop the remaining analytical research program. Therefore, it is important that the majority of these efforts be completed before the research plan is developed.

The analytical research effort will include the use of pertinent data obtained from the above studies and it should consist of modeling techniques aided by laboratory investigations. It is recommended that the following topics receive priority:

- Formulate a consistent approach for the structural analysis and design of work platforms with major emphasis on material properties, loading configuration, capacity reduction factors, safety factors and a defined design strength.

- Develop mathematical models for computer analysis of the various types of scaffolds, including constraints, support displacements, connection and anchorage force resultants and displacements, and tie down and guying effects, under various loading configurations.

- Apply ultimate and working stress design concepts to scaffolding systems and their components.

- Develop minimum performance criteria for anchors, connections, wheels and locking devices by laboratory investigations.

- Perform anchor-foundation pul1-out strength studies to establish ultimate anchor limit states, especially on anchors embedded in partially cured concrete.

- Conduct human loading effects on scaffold platforms and other components including step-down and impact tests via human subjects and an anthropomorphic dummy .

The technical data obtained from the above effort will be analyzed and used as basis for establishing a set of scaffolding safety criteria. These criteria can then be used to upgrade scaffolding provisions in existing codes and standards to enhance safety in the design and application of scaffolding systems to construction practice. 


\section{REFERENCES}

1. Fattal, S.G., Mullen, C.L., Hunt, B.J., Lew, H.S., Analysis of Scaffolding Accident Records and Related Employee Casualties, NBSIR 79-1955 National Bureau of Standards, Washington, D.C., January 1980.

2. American National Standard, Safety Requirements for Scaffolding, et al. (ANSI A10.8, A92.1, .2, .3, .6), The American National Standards Institute, New York, NY, 1971.

3. Occupational Safety and Health Standards, (Federal Register 29 CFR Part 1910), Occupational Safety and Health Administration, U.S. Department of Labor, Washington, D.C., 1974.

4. Construction Safety and Health Regulations, (Federal Register 29 CFR Part 1926), Occupational Safety and Health Administration, U.S. Department of Labor, Washington, D.C., 1974.

5. State of California Construction Safety Orders (CAL/OSHA), Building News, Inc., Los Angeles, CA, January 1976.

6. The National Building Code, American Insurance Association, New York, NY, 1976.

7. The BOCA Basic Building Code, Building Officials and Code Administrators International, Inc., Chicago, IL, 1978.

8. Canadian Construction Safety Code, National Research Council of Canada, Ottawa, Canada, 1977.

9. State of California Administrative Code, Fifth printing, Sacramento, CA., 1926.

10. Construction Safety Code, State of Connecticut Labor Department, Wethersfield, CT.

11. Wisconsin Administrative Code, Madison, WI, 1971.

12. Building Code of Atlanta, Atlanta, GA, 1973.

13. Building Code of the City of New York, Chapter 26, Administrative Code, New York, NY, 1974.

14. Lew, H.S., Fattal, S.G., Shaver, J.R., Reinhold, T.A., Hunt, B.J., Investigation of Construction Failure of Reinforced Concrete Cooling Tower at Willow Island, West Virginia, NBSIR 78-1578 National Bureau of Standards, Washington, D.C., Noyember 1979.

15. Eisenacher, E.A., Evaluation of OSHA Scaffolding Standards, Newport News Shipbuilding, Newport News, VA, 1979. 
16. Manual of Steel Construction, American Institute of Steel Construction, Inc., New York, NY

17. Timber Construction Manual, American Institute of Timber Construction, John Wiley and Sons, New York, NY, 1974.

18. Building Code Requirements for Reinforced Concrete, ACI 318-77, American Concrete Institute, Detroit, MI, 1977.

19. Results of Steel Scaffold Testing, Scaffolding and Shoring Institute, Cleveland, OH, 1961, 1963, 1966. 
TABLE 1. TYPES OF SCAFFOLDS ADDRESSED BY ANSI AND OSHA

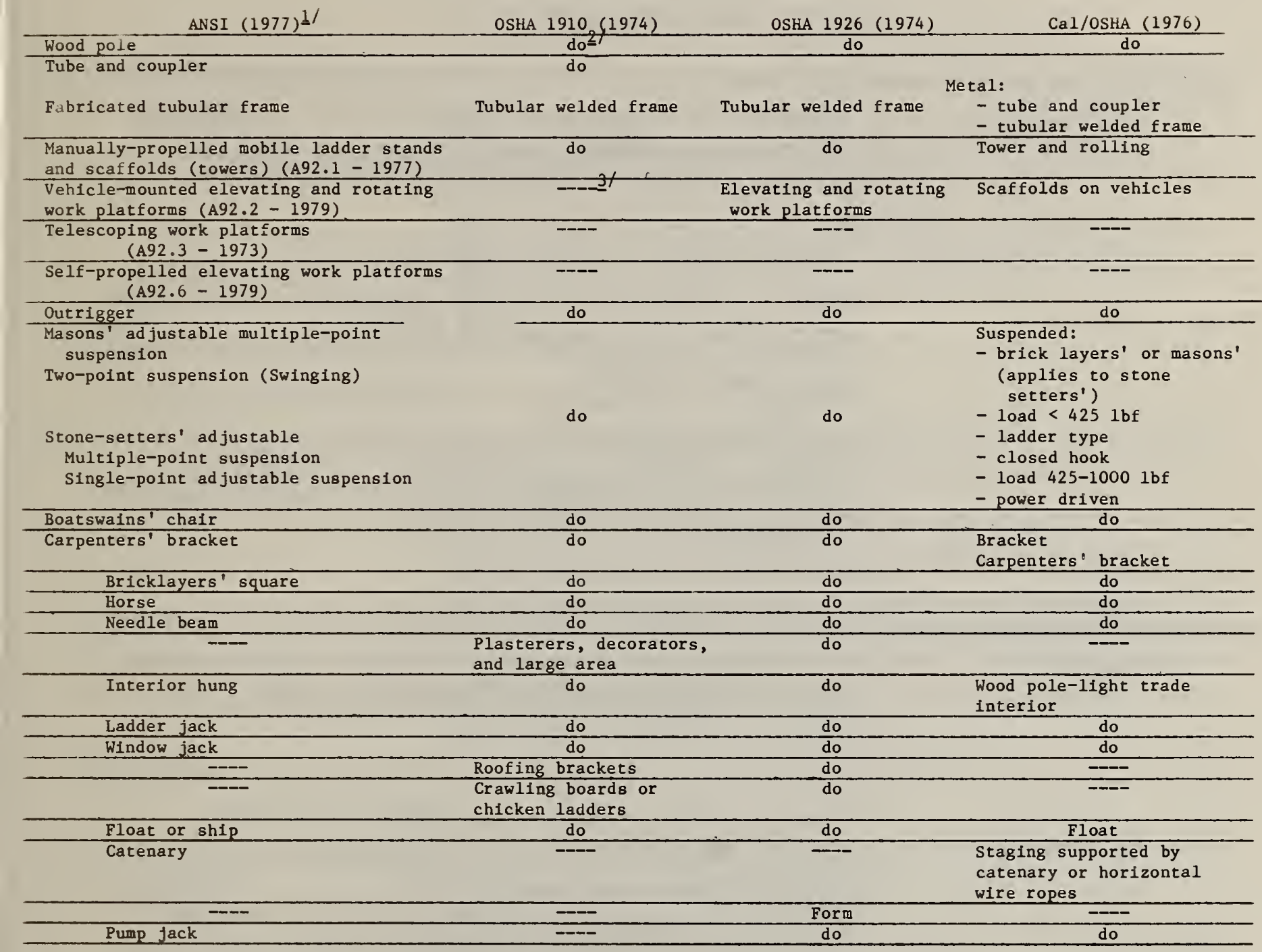

$1 /$ Unless otherwise noted, ANSI A10.8 is referenced.

$2 /$ "do" is an abbreviation for "ditto", implying that the same term is used as that which is used in the first column by ANSI.

3/ A dashed line implies that the type is not discussed in the particular standard. 
Table 2a. General Provisions for Scaffolding (ANSI)

AMERICAN NATIONAL STANDARDS INSTITUTE

AMERICAN NATIONAL STANDARD

ANSI AI0.8 (1977)

1. Work Platform

a. Planking 2-in (nominal) thickness selected for plank use recognized by grading rules 1 for species used.

b. For 2 x 10-in (nominal) or $2 \times 9$-in (rough) planks:

Span $(f t) \leq \begin{array}{r}10 \\ 8 \\ 7\end{array} \quad$ for Working Load $\left(1 \mathrm{bf} / \mathrm{ft} t^{2}\right) \leq \begin{array}{r}25 \\ 50 \\ 75\end{array}$

c. Span $\leq 4 \mathrm{ft}$ for 1-1/4 $\mathrm{x} 9$-in or wider plank of full thickness with medium loading of $50 \mathrm{lbf} / \mathrm{ft}^{2}$.

d. Fabricated planking may be used if it meets general strength requirement (item 6).

e. Planks laid with opening $<1$ in between adjacent planks or scaffold member.

f. Planks or platforms in continuous run overlapped $\geq$ in or secured from movement.

g. Unless restrained at both ends, planks extend 6-18 in over end supports.

2. Supporting

Elements a Load-carrying timber members of scaffold framing minimum of $1500 \mathrm{lbf} / \mathrm{in}^{2}$ (stress grade) construction grade lumber.

b. Rope for suspension supports $\geq 6 \times$ (intended load).
3. Connections and Anchorages a. Nails or bolts develop at each connection designed strength of scaffold.

b. Scaffolds secured to permanent structures. Do not use window cleaner's anchor bolts.

c. Check ties and scaffold components to which ties are attached for additional load due to wind and weather if scaffold partly or wholly enclosed.
4. Foundation

5. Accessway
Footing or anchorage sound, rigid, capable of supporting maximum intended load without settling or displacement.

6. Strength

Scaffolds and their components support without failure

$\geq 4 \mathrm{x}$ (maximum intended load).

1/ Crading rules approved by the board of review of the American Lumber Standards Comm1t tee. 


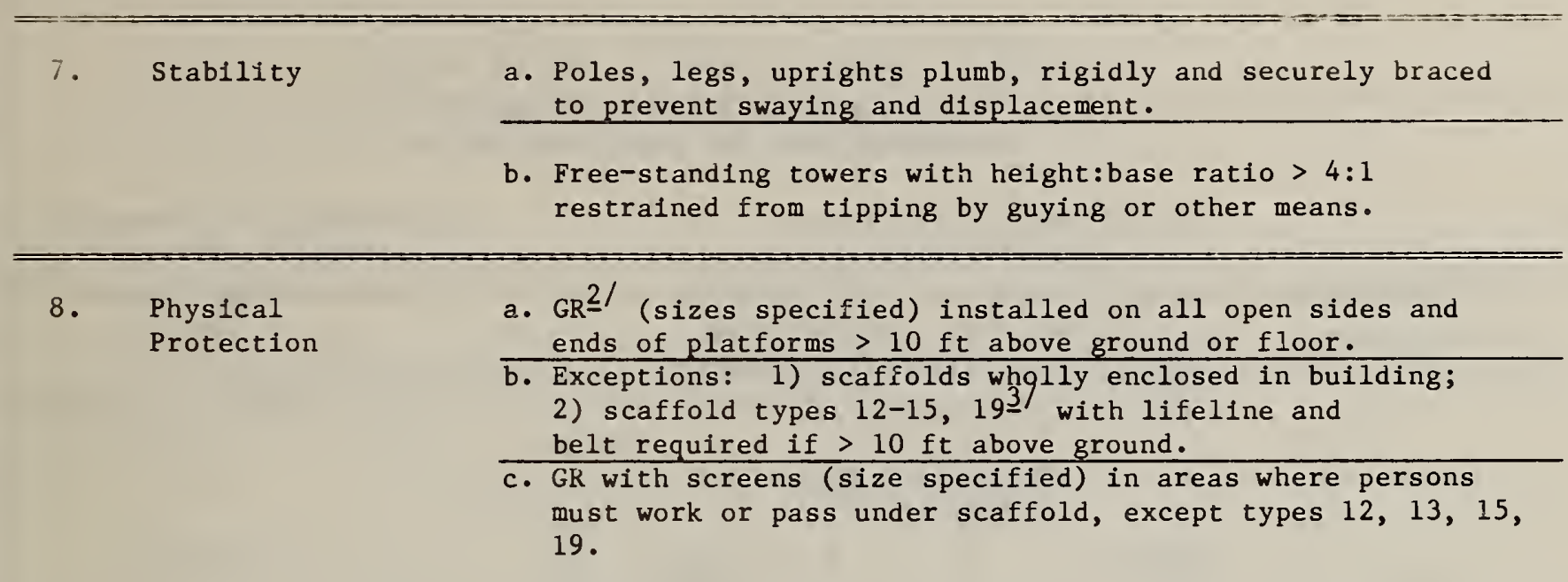

9. Environmental
Safety Criteria

a. Overhead protection for men on a scaffold exposed to overhead hazards.

b. Workers shall not work on scaffolds during storms or high winds or on scaffolds covered with ice or snow unless removed and planking sanded.

c. Tools, materials, debris not accumulated on platforms.

d. Treat fiber or synthetic rope if corrosive substance used. Acids or corrosive substances not used on scaffolds unless approved by manufacturer.

e. Protect scaffold members, wires, fiber, synthetic rope when using heat producing process.

\section{Special \\ Provisions} a. Scaffolds not to be loaded in excess of load for which
intended.

b. Manufactured scaffolds used in accordance with manufacturers recommendations.

c. Scaffolds not named or defined in this standard prohibited unless exception granted by enforcing authority.

d. Scaffold designed by qualified engineer for type $1>60 \mathrm{ft}$ high or types $2,3>125$ ft high.

\footnotetext{
$2 /$ 'GR' is an abbreviation for 'gaurdrails' assumed to consist of toprail, midrail and toeboard.

3/ Scaffold types numbered and described in Appendix B.
} 
Table 2b. General Provisions for Scaffolding (OSHA)

UNITED STATES DEPARTMENT OF LABOR

OCCUPATIONAL SAFETY AND HEALTH ADMINISTRATION

Occupational S. \& H. Standards OSHA 1910 (1974)
Construction S. \& H. Standard OSHA $1926(1974)$

1. Work Platform

a. All planking shall be Scaffold Grade

cf. OSHA 1910 recognized by grading rules for species used.

b. For $2 \times 9-1$ or wider planks: For $2 \times 10-1 \mathrm{n}$ or wider planks:

Full thick. Nom.
Undressed thick.

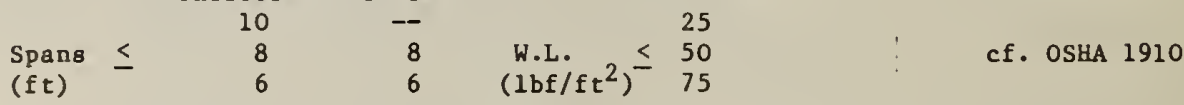

\begin{tabular}{|c|c|}
\hline c. cf.4/ ANSI & cf. ANSI \\
\hline d. & 0 \\
\hline e. & 0 \\
\hline f. cf. ANSI & cf. ANSI \\
\hline $\begin{array}{l}\text { g. } \\
\text { (End restraint not mentioned.) }\end{array}$ & $\begin{array}{l}\text { Planks extend } 6-12 \text { in. over end } \\
\text { supports. }\end{array}$ \\
\hline
\end{tabular}

2. Supporting

\begin{tabular}{cc} 
a. $\operatorname{ANSI} \star \underline{6} /$ & cf. OSHA 1910 \\
\hline b. $\quad$ cf. ANSI & cf. ANSI* \\
& *fated load")
\end{tabular}

3. Connections and

a.

cf. ANSI

Anchorages

Also nails not subjected to straight pull;

nalls driven full length.

\begin{tabular}{cccc}
\hline b. & cf. ANSI & & \\
\hline$c$. & 0 & 0
\end{tabular}

5. Accessway

cf. ANSI

cf. OSHA 1910

(Restraint not mentioned.)

4/ 'Confero', Latin meaning 'compare with' connoting 'similar to' as used.

5/ An open-dot depicts 1 tems not addressed by the particular code or standard.

${ }_{6}^{\prime}$ A clagle asterisk depicts an unclear situation where wording lacks definition, thus 1nh1b1ting interpretation of 1ntent. 

6. Strength
cf. ANSI
cf. ANSI

\begin{tabular}{llll} 
7. Stability & cf. ANSI & cf. ANSI \\
\cline { 2 - 3 } & b. & 0 & 0
\end{tabular}

8.
Protection

having minimum horizontal dimension $<45$ in.

\begin{aligned} & b. Exceptions: cf. ANSI \\ & 2) $\begin{array}{l}\text { scaffold types 13,14 } \\ \text { in use by structura1 } \\ \text { iron workers. }\end{array} \\ &$\hline c. cf. ANSI (noexceptions stated) \end{aligned}

Exceptions: types 13, 14. cf. OSHA 1910

9. Environmental Safety Criteria

\begin{tabular}{ll} 
a. & cf. ANSI \\
\hline b. & cf. ANSI \\
\hline c. & cf. ANSI \\
\hline d. & $\begin{array}{c}\text { cf. ANSI } \\
\text { When acid solutions used for cleaning } \\
\text { buildings > } 50 \text { ft high use wire rope } \\
\text { supported scaffolds. }\end{array}$ \\
\hline cf.
\end{tabular}

cf. ANSI Slippery conditions eliminated as soon as possible after they occur.

e. cf. ANSI

cf. ANSI

No welding, burning, riveting, open flame work on staging suspended by fiber or synthetic rope.

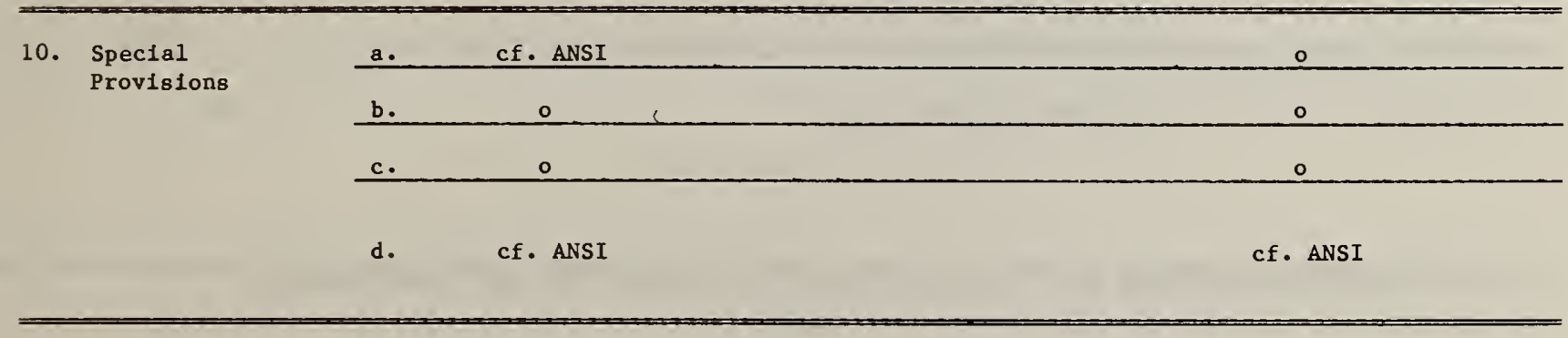


Table 2c. General Provisions for Scaffolding (NBC and BOCA)

American Insurance Association

National Bullding Code NBC 1201 (1976)
Bullding officials and Code Administrators Basic Bullding Code BOCA 1314 (1978)
1. Work Platform

a. Where wood planking used, cf. OSHA 1910.

$\star^{71}$
Platforms and supporting elements** designed, constructed to support uniform minimum live loads in $1 \mathrm{bf} / \mathrm{ft} \mathrm{t}^{2}$ of platform area in accordance with following:

\begin{tabular}{clc} 
Class & \multicolumn{1}{c}{ Service Type } & Load \\
\hline $\begin{array}{c}\text { Light } \\
\text { Duty }\end{array}$ & $\begin{array}{l}\text { Carpenters } \\
\text { Stone setters (no stone) } \\
\text { Miscellaneous (no mater1al) }\end{array}$ & 25 \\
\hline $\begin{array}{c}\text { Medium } \\
\text { Duty }\end{array}$ & $\begin{array}{l}\text { Br1cklayers } \\
\text { Stucco } \\
\text { Lathers, P1asterers }\end{array}$ & 50 \\
\hline $\begin{array}{r}\text { Heavy } \\
\text { Duty }\end{array}$ & Stone masons & 75
\end{tabular}

2. Supporting

Elements

a. Where load carrying members are wood, use

stress graded lumber, having extreme

flber stress in bending, $f>1200$ psi.

**

b.

cf. ANSI

3. Connections and
6. Strength
cf. ANSI but $\geq 100 \mathrm{lbf} / \mathrm{ft}^{2}$
cf. ANSI

If The double aster1sk shows which categorles within a code share the same cross-reference. 
a.

8. Physical Protection cf. OSHA 1926

b. Exceptions: 1) 0 2) cf. OSHA 1910
cf. ANSI
c.$$
\text { cf. ANSI }
$$

All floor and wall openings shall be protected with substantial guardrails and toe boards in accordance with accepted engineering practice.
9. Environmenta1 Safety Criteria
a. Overhead protection ( $<10 \mathrm{ft}$ above plat- form) capable of supporting objects likely to fall.

o

b-d $\circ$
e. Provisions (specifled) where scaffolds materials require fire protection.


Table 2d. General Provisions for Scaffolding (NRCC)

National Research Council of Canada

Canadian Construction Safety Code

NRCC 15562 (1977)

1. Work Platform

a. Wood** platforms have planks of same thickness

$>2 \times 10-i n$ (nominal).

b. For $2 \times 10$-in (nominal) planks, span $\leq 8 \mathrm{ft}$, and

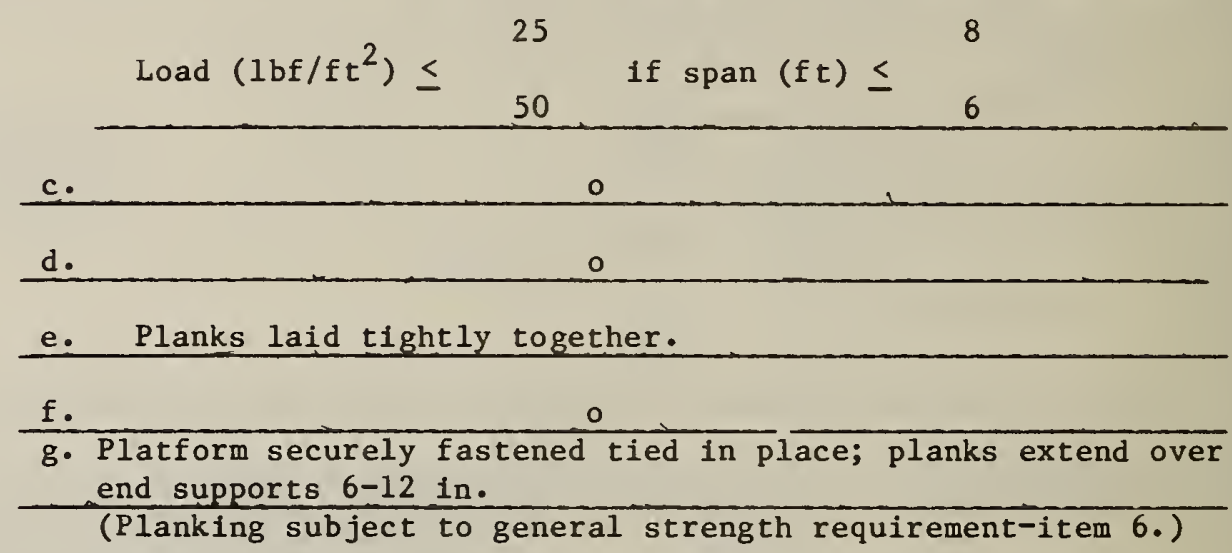

2. Supporting

Elements

a. Material used in construction of scaffold shall be suitable for intended use. Where lumber used** it shall be $>$ strength of No. 1 Spruce.

b. No general provision.

3. Connections and Anchorages
Horizontal members shall not be spliced between points of support.

(Joints subject to general strength requirement-item 6.)

4. Foundation

cf. ANSI

5. Accessway

Except for suspended scaffolds, platform $>5 \mathrm{ft}$ above level workman may fall provided with means of access and egress (specified).

6. Strength

Scaffold including joints and planking shall be

capable of supporting $\geq 4 \mathrm{x}$ (maximum intended load). 
a. Uprights shall be adequately braced diagonairy and horizontally to prevent lateral movement.

b. Scaffold adequately secured to suitable supports at vertical intervals $\leq 3 \times$ (least base dimension).

\section{Physical Protection}

a. GR at areas to which workman has access and may fall into water or vertical drop >10 ft; where wheelbarrows or other vehicles used $G R$ when drop $>4 \mathrm{ft}$.

b. Use wood GR (sizes specifled); wire cable and snow fencing may be used unless prohibited by appropriate authority having jurisdiction.

c. GR with screens (size specified) where required by appropriate authority having jurisdiction.

d. Safety belt and independent lifeline for suspended scaffolds.
9. Environmental Safety Criteria
Barrels, boxes or similar loose objects shall not be used to stand upon while working; top rails of GR shall be free from splinters or protruding nails.
10. Special Provisions $\mathrm{a}-\mathrm{b}$

c. Scaffolds or components thereof that do not comply in all respects with provisions of this code shall not be used unless approved for such use.

d. Temporary works shall be designed by a professional engineer competent and experienced in this type of work where required by appropriate authority having jurisdiction or scaffold $>30 \mathrm{ft}$ high. 
Table 2e. General Provisions for Scaffolding (Cal/OSHA)

State of California

Administrative Code-Industrial Relations

Construction Safety Orders

Cal/OSHA 29 (1976)

1. Work Platform

a. Except when specified, planks 2-in (nominal) material selected for scaffold grade plank (defined).

\begin{tabular}{lc} 
b. & cf. ANSI \\
\hline c. & cf. ANSI \\
\hline d. & cf. ANSI \\
\hline e. & No general provision. \\
\hline f. & No general provision.
\end{tabular}

g. Plank overhang its support $\leq 18 \mathrm{in}$, unless access to overhanging portion prevented or unless other end of plank anchored.

2. Supporting Elements

\begin{tabular}{ll} 
a. No general provision. & cf. ANSI, * \\
\hline b. & $\begin{array}{l}\text { under type-specific provision } \\
\text { * ("factor of safety of } 6 ")\end{array}$
\end{tabular}

3. Connections and Anchorages

cf. ANSI; also, nailed joints not support concrete hoppers with capacity $>1 / 2 \mathrm{yd}^{3}$; nalls $\geq 8$-penny size; minimum number of nails specified for various connection types and size lumber; lubricated or wax-coated nalls not used.

4. Foundation No general provision.

5. Accessway

Safe and unobstructed means of access, such as walkway, stair, or ladder provided to platform.

\section{Strength}

cf. ANSI* (Inspection and replacement of pleces

not meeting requirement called for - test 1 mplied.) 
7. Stability

a. Anchorage and bracing shall prevent scaffold from swaying tipping, or collapsing.

b.

0

8. Physical

Protection a. GR (sizes specified) on all open sides and ends of elevations > 7-1/2 ft above level below.

b. Exceptions: scaffold types 15, 19

c. cf. ANSI, if material on a railed scaffold is piled higher than the toeboard (canvas and equivalents to 1/2-in wire mesh permitted).

d. Provisions for use of safety belts and nets.
9. Environmental Safety Criteria

\begin{tabular}{|c|c|}
\hline b. & $\begin{array}{l}\text { Worker not permitted to work on platform where } \\
\text { slippery conditions exist unless such conditions are } \\
\text { a necessary part of the work. }\end{array}$ \\
\hline c. & cf. ANSI \\
\hline
\end{tabular}

d-e o
10. Special
Provisions $\mathrm{a}-\mathrm{b} \quad \mathrm{cf}$. ANSI

c. Scaffolds constructed of wood or suitable materials such as steel or aluminum members of known strength characteristics. Where materials other than wood used or scaffold designs differ from provisions in these orders, equivalent strength, rigidity, safety must be provided.

d. cf. ANSI, professional engineer currently registered in California; some reductions in permissible height for several working levels on same scaffold. 
Table 2f. General Provisions for Scaffolding (State Authorities)

State of Wisconsin

Wisconsin Administrative Code

Rules of Industry, Labor, and Human Relations (1971)
State of Connecticut

Labor Vepartment Construction Safety Code (1971)
1. Work

Platform a. cf. NRCC

b. Span $\leq 8 \mathrm{ft}$, except for printing, decorating, and paper work (conditions given). Safe load Is proportional to allowable stress, also varies according to load distribution assumed (examples shown for one species and one allowable stress).

$\frac{c-d}{\text { e. Platform to be solld, except spacing } \leq 18 \text { in }}$

permitted for $11 \mathrm{ght}$ work (defined).

f. Two successive planks not to abut on a single bearer; where overlap, ends of upper and lower planks overlap bearer $\geq 6 \mathrm{in}$.

Except where otherwise specifled:

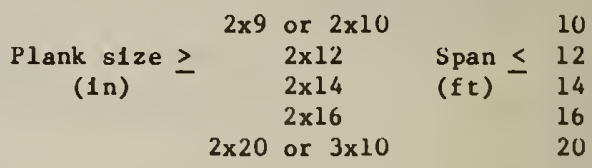

8. Planks shall project over last bearer
6-12 1n.
$\begin{aligned} & \text { (Subject to general strength requirements - } \\ & 1 \text { tem } 6 .)\end{aligned}$
1 tem 6.) 1tem 6.)

2. Supporting Elements $a-b$ (Subject to general strength requirements 1 tem 6.)
(Subject to general strength requirements 1tem 6.)

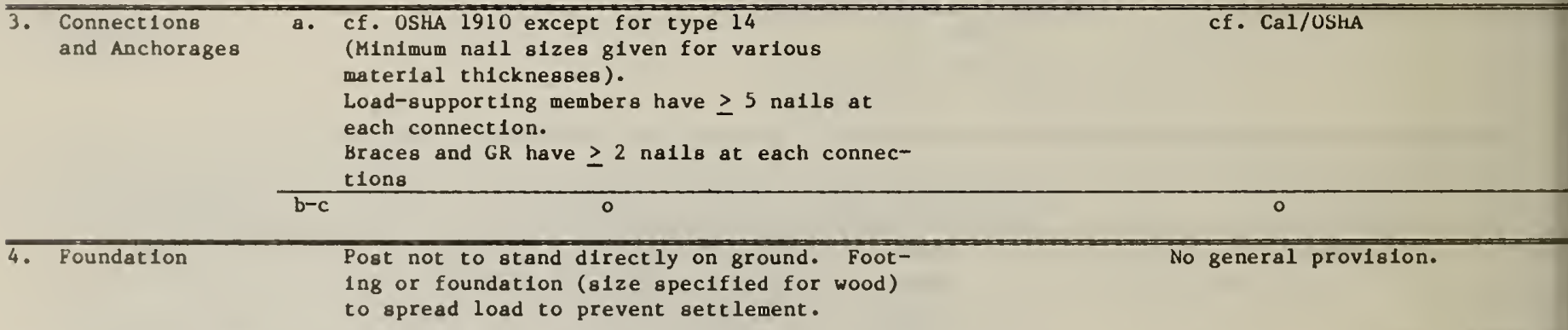

5. Accessway

\begin{abstract}
Lumber to be stress grade material, carrying 1 mposed loade safely without exceeding allowable working stresses (specified). Metal to conform w1th ASTM standards (g1ven). All scaffolds designed and bullt so unit stresses in material under maximum loading $\geq 8$ pecified. Yactor of safety of 4:1 for metal scaffolds.
\end{abstract}

Lumber equivalent of "selected lumber" free from damage that affects 1 ts strength. Replace pieces of lumber that cannot support 4 x (maxipym load to be 1mposed). Reference SSSI 9 for allowable stresses and safety factors for metal scaffolds. Factors of safety of 6 for suspension rope.**

\footnotetext{
American Society for Testing and Materialo

$2 /$ Steel Scaffolding and Showing Institute.
} 
b.

$\circ$
Free-standing towers or rolling scafiolds to have least base dimension $\geq 1 / 3$ height unless guyed.

\section{Physical}

$\circ$

\section{Protection}

\begin{tabular}{ll} 
a. & \multicolumn{1}{c}{ cf. ANSI } \\
\hline b. & $\begin{array}{l}\text { Exceptions: riveter's platforms, s } \\
\text { types 18,19, and single plank } \\
\text { painters scaffolds. }\end{array}$ \\
\hline c. & cf. Cal/OSHA \\
\hline d. $\quad \begin{array}{l}\text { Independent lifelines for suspended } \\
\text { scaffolds }\end{array}$
\end{tabular}
a. cf. ANSI
Exceptions: riveter's platforms, scaffold
olds.

Exceptions:

1) cf. ANiSI

2) cf. ANSI

o

9. Environmental

Safety Criteria

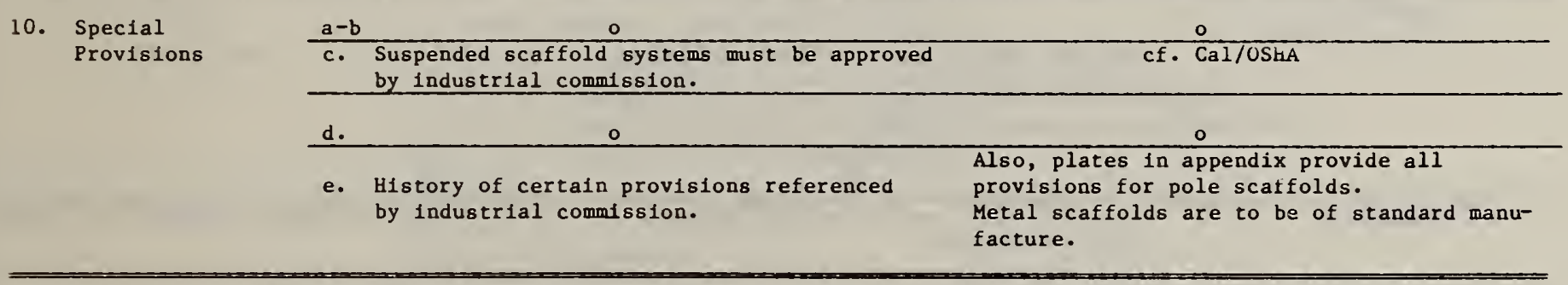


Table 2g. General Provisions for Scaffolding (Municipal Authorit1es)

City of New York

Bullding Code

(1968 - amendments through 1974)
City of Atlanta

Building Code

(1973)
1. Work Platform $\circ$

b. For 2-1n plank8:

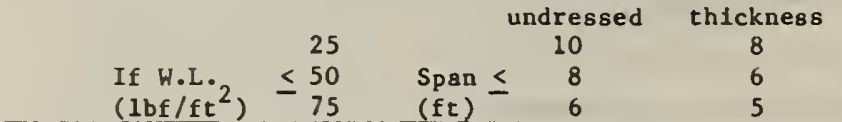

c. For $1-1 / 4-1$ in plank of full thickness

8pan $<6 \mathrm{ft}$, work1ng load $\leq 50 \mathrm{lb} / \mathrm{ft}^{2}$

$\frac{0}{\text { d. }}$

\begin{tabular}{cc}
\hline f. & 0 \\
\hline$g$. & cf. ANS I
\end{tabular}

Planks $\geq 2-1$ (nominal) thickness of

sound, seasoned lumber.
2. Supporting Elements

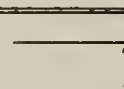

to be carried) through distance of 1

to be carried) through distance of $1 \mathrm{ft}$; wire

rope support $6 \times$ (actual load).

3. Connections and Anchorages a.

cf. ANSi

(Minimum requirement for sizes and number

of nalls specified). $\star \star$ cf. ANSI

c.

4. Poundation 
7. tability

a. $\circ$

Adequate cross-bracing for uprights.

b.

cf. ANSI

$\hbar \star$

8. Physical
Protection

a. cf. ANSI unless ocherwise specifled for particular type of scaffold.

\begin{tabular}{lcc}
\hline b. & $\circ$ & \\
\hline c. & cf. ANSI
\end{tabular}

GR (heights specified, not sizes) if platform $>20 \mathrm{ft}$ above ground or $6 \mathrm{ft}$ above floor level.

Exceptions: Iron workers' scaffolds and type 16

Screens (size not specified) if material

higher than toe boards.
9. Environmental Safety Criteria a.

b. Falling tools or debr

d.

e. Except planking, use noncombusitble material (conditions specified). cf. ANSI

Platforms and supports noncombustible material or treated wood (conditions specified).

10. Special Provisions

a. cf. ANSI (standard loads defined).

b. Construction of designed scaffolds in accordance with designs.

c. Materials or dimensions other than specified may be used if equivalent to compar able scaffold and approval of commissioner obtained.

d. Type 1 scaffolds $>75 \mathrm{ft}$ and all type 9 scaffolds shall be designed; drawings kept at site. 

APPENDIX A

2.1 Major Types of Scaffolds Under Study 
1 Wood pole scaffold

a) single post.................... A

b) double post................... A-4

2 Tube and coupler scaffold.......................... A

3 Fabricated tubular frame scaffold......................

4 Manually propelled mobile ladder stand and scaffold tower..... A-8

5 Vehicle-mounted elevating and rotating.................. A

6 Telescoping work platform....................... A

7 Self-propelled elevating work platform................ A-9

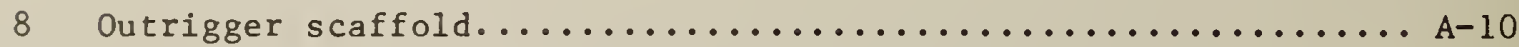

9 Ad justable multiple-point suspension (masons' or stonesetters') scaffold.................................. A-

10 Two-point suspension (swinging) scaffold............... A-11

11 Single-point suspension scaffold..................... A-11

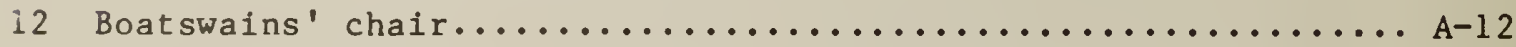

13 Needle beam scaffold.............................. 12

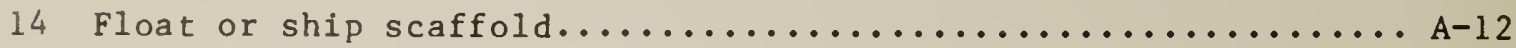

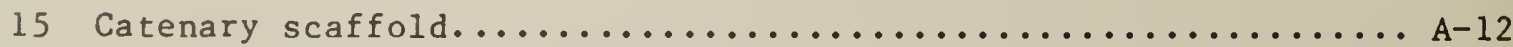

16 Bracket (carpenters' bracket) scaffold.......................

17 Square (bricklayers' square) scaffold.........................

18 Horse scaffold...................................

19 Ladder jack scaffold............................... 15

20 Window jack scaffold................................

21 Pump jack scaffold................................ 


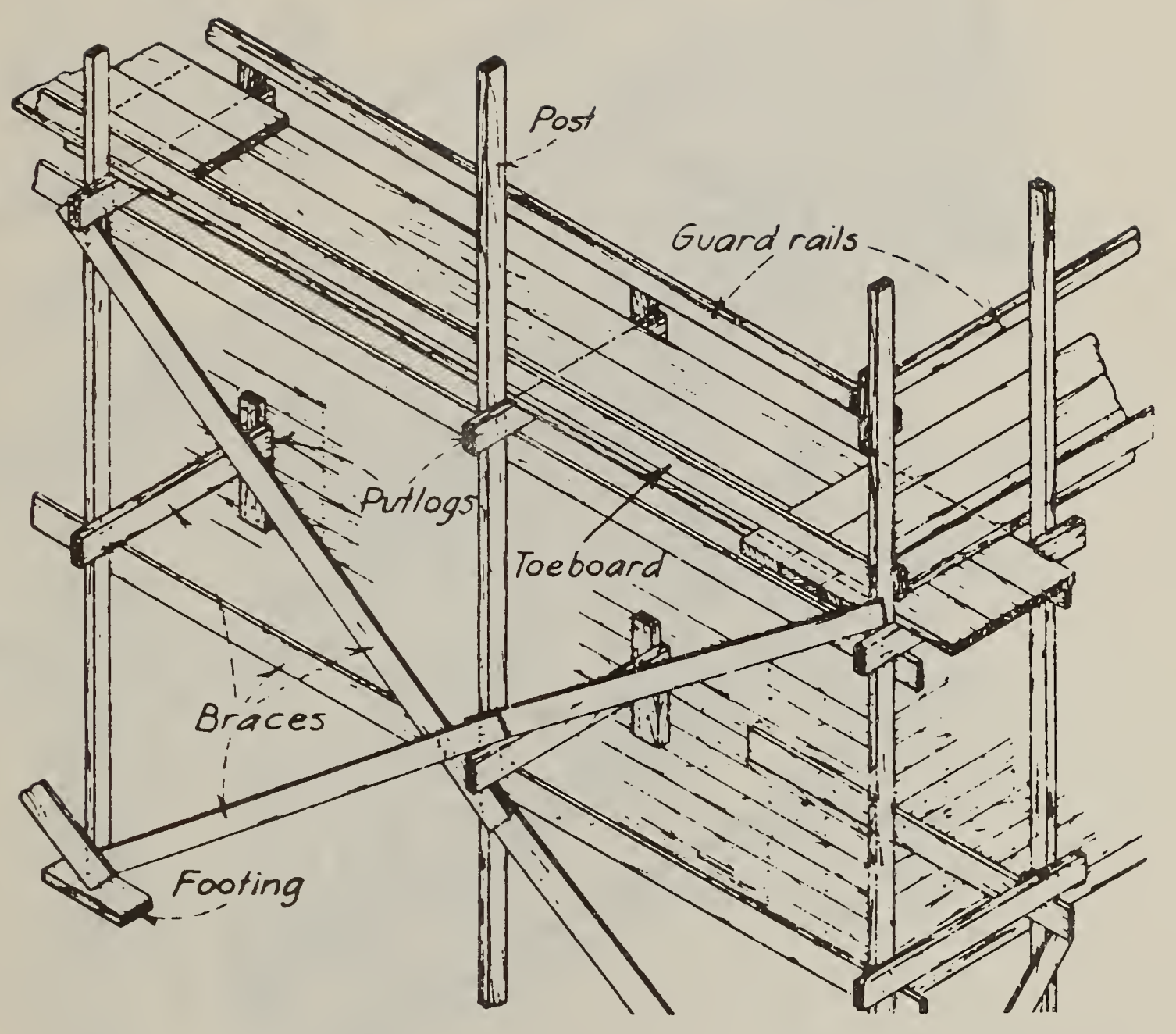

Type $1 \mathrm{a}$

Figure A.1. Wood pole scaffold - (a) single post. 


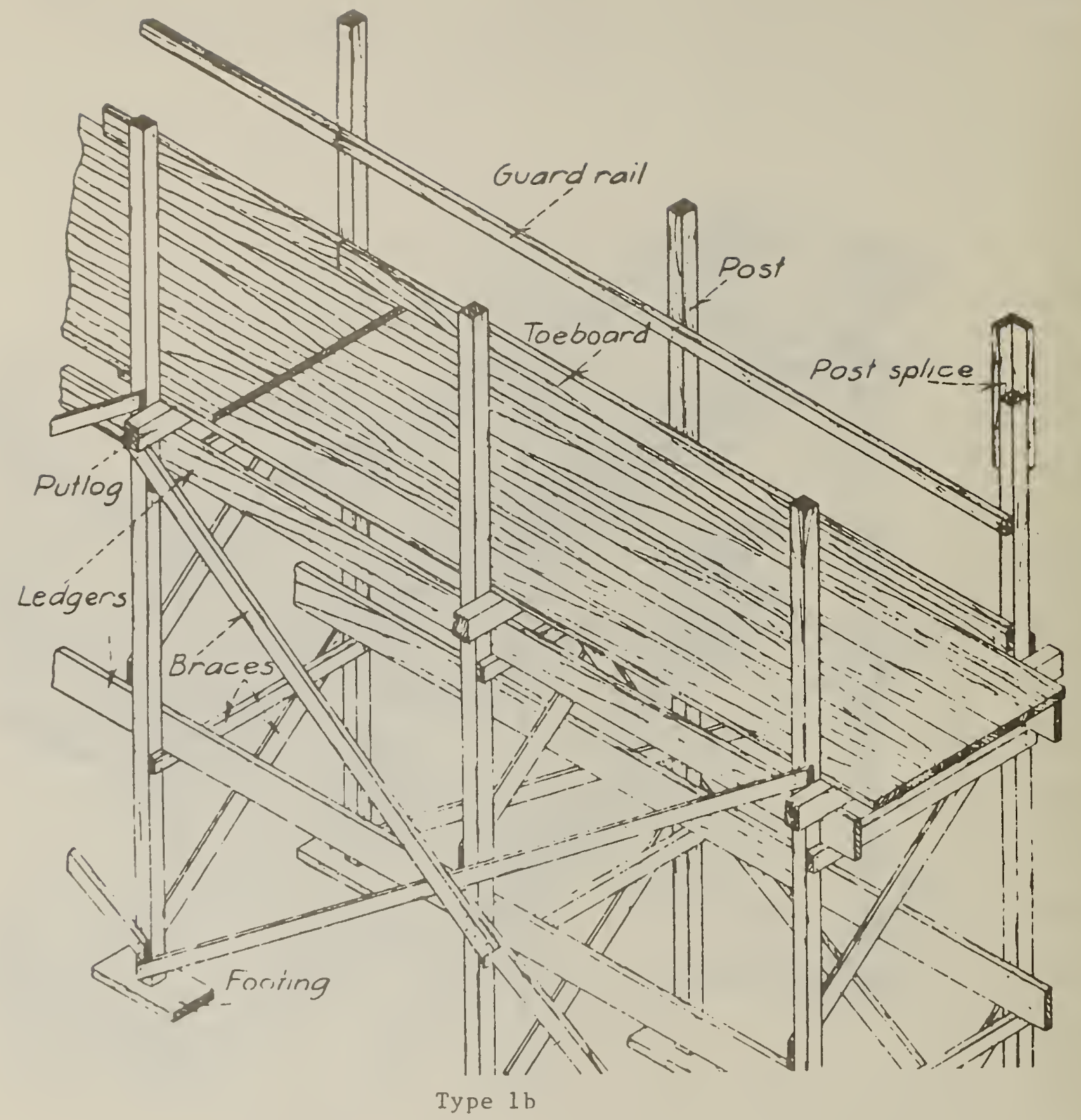

Figure A.l. Wood pole scaffold - (b) double post 

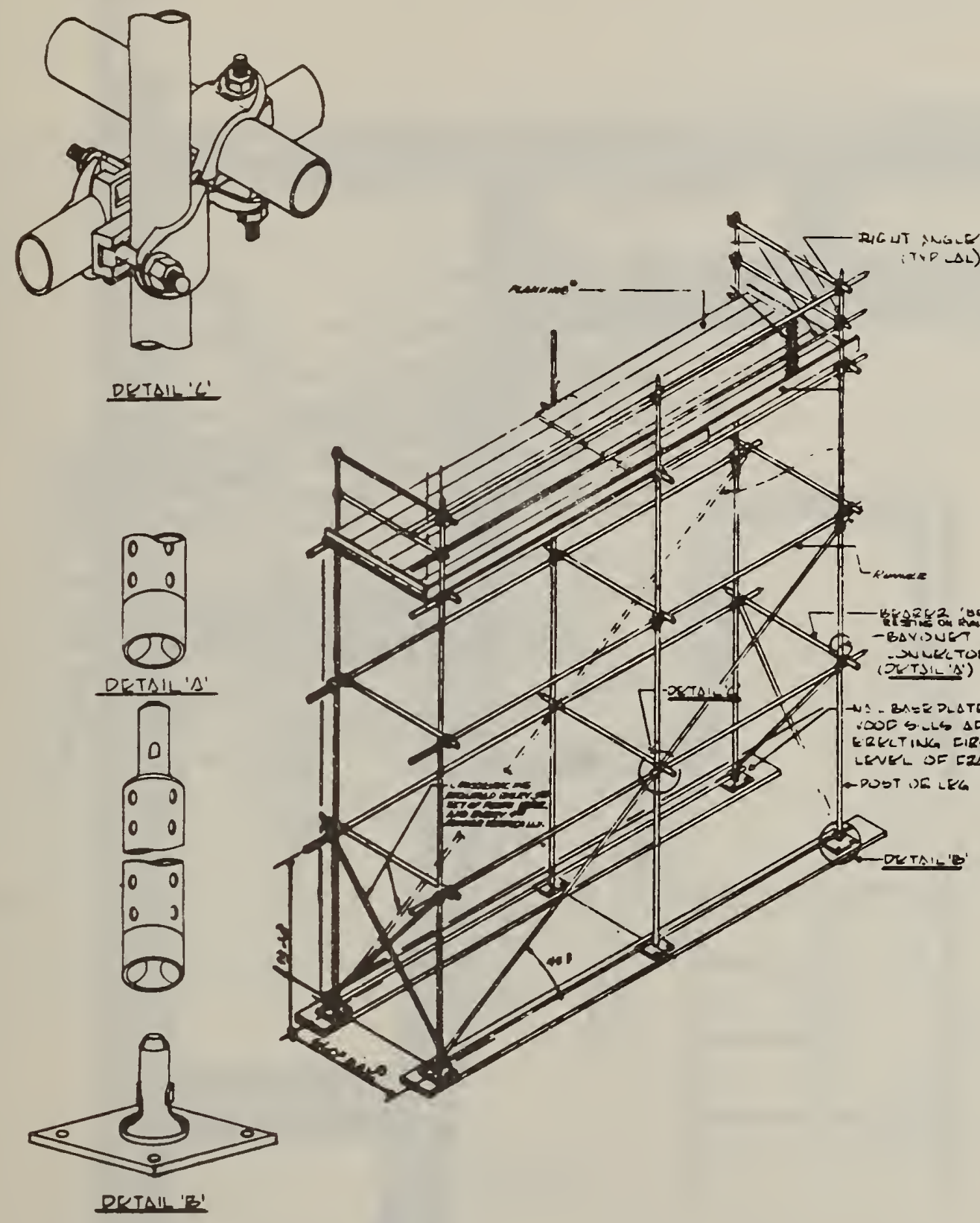

Type 2

Figure A.3. Tube and coupler scaffold. 


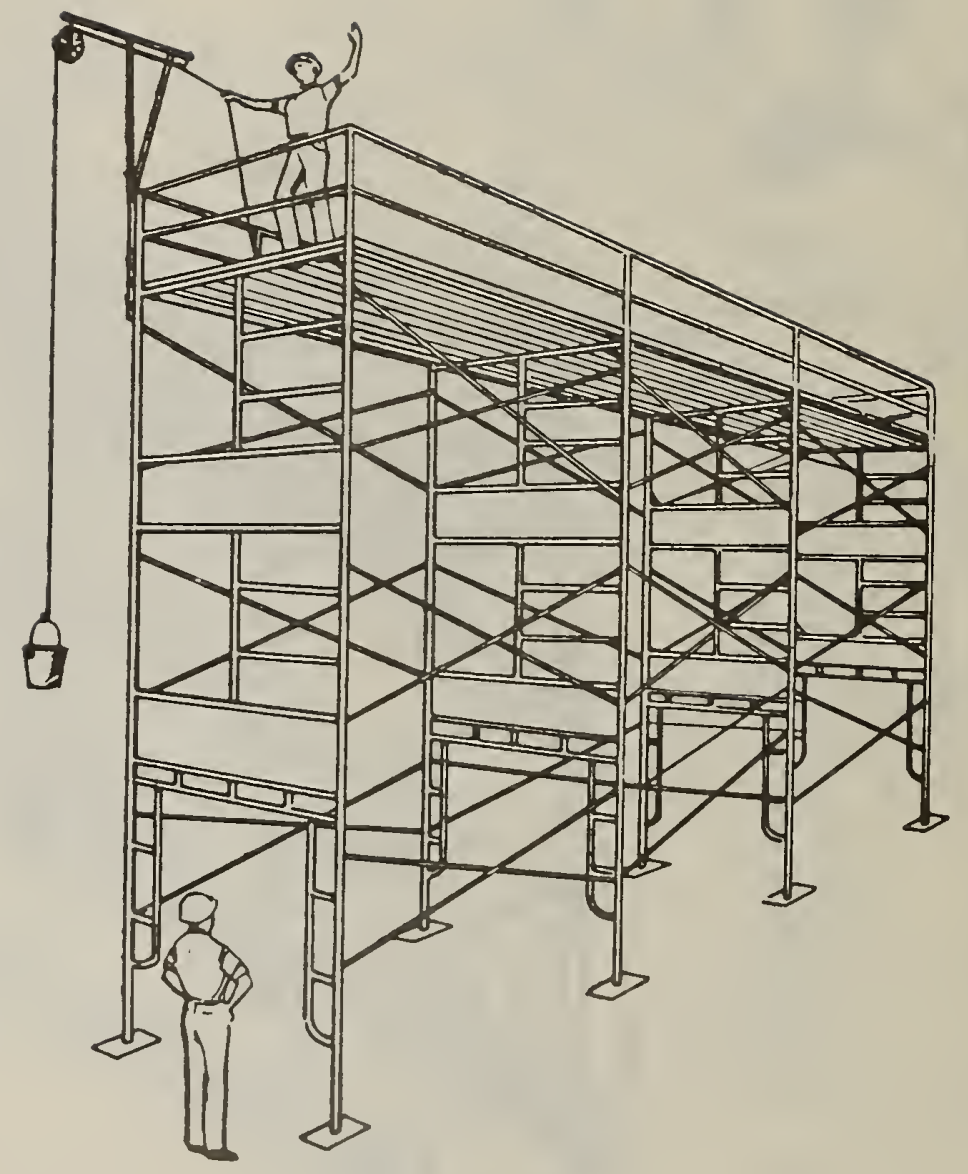

Type 3

F1gure A.4. Fabricated tubular frame scaffold. 


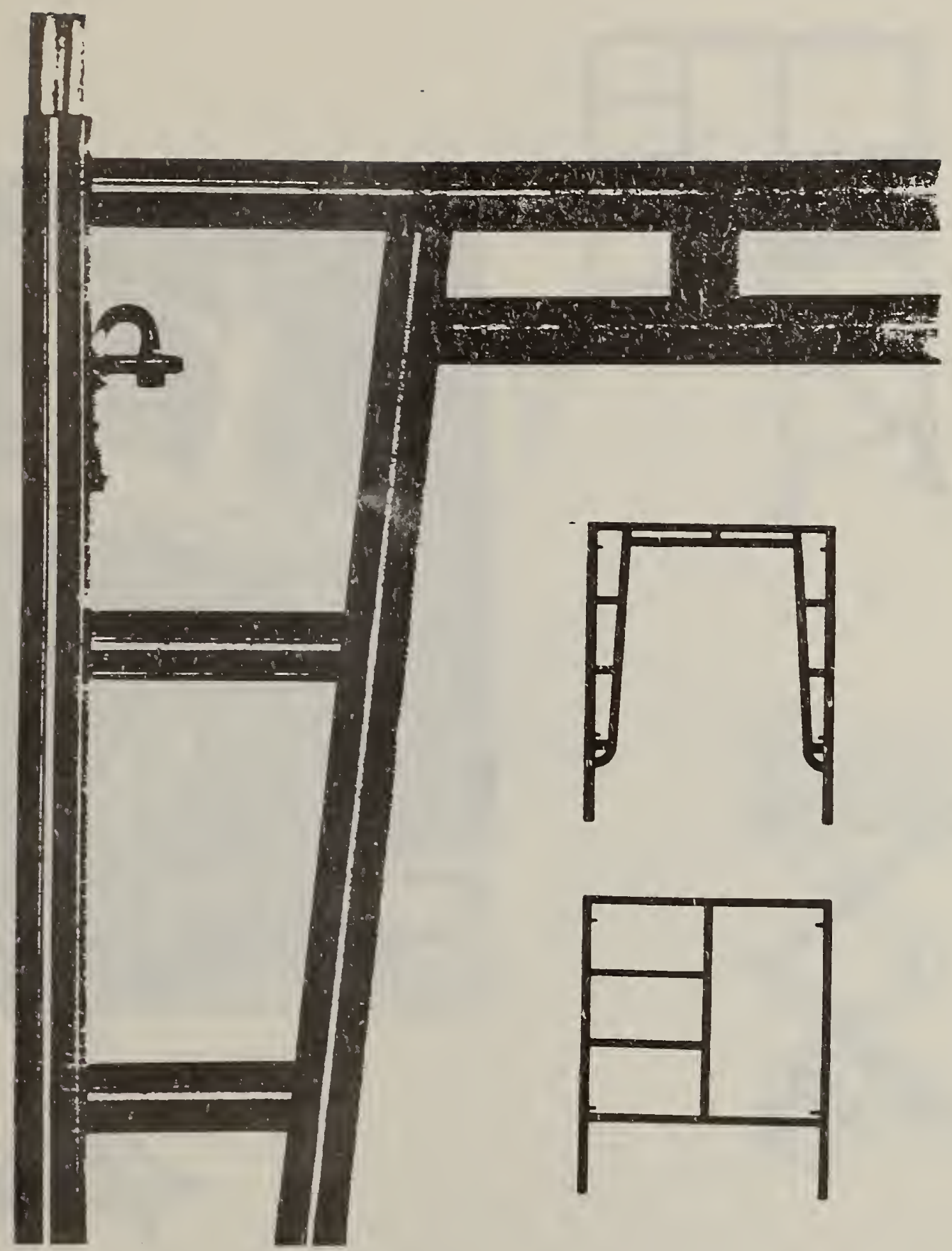

Figure A.5. Tubular frame subsystems.

A-7 


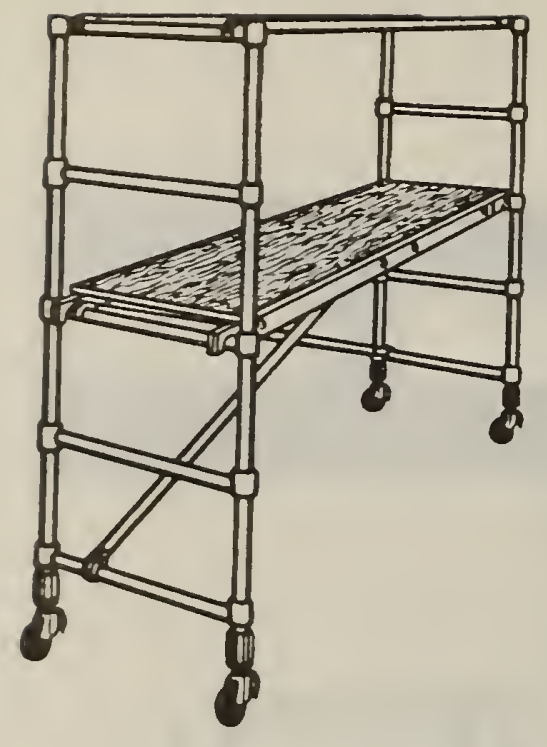

(a) Type 4

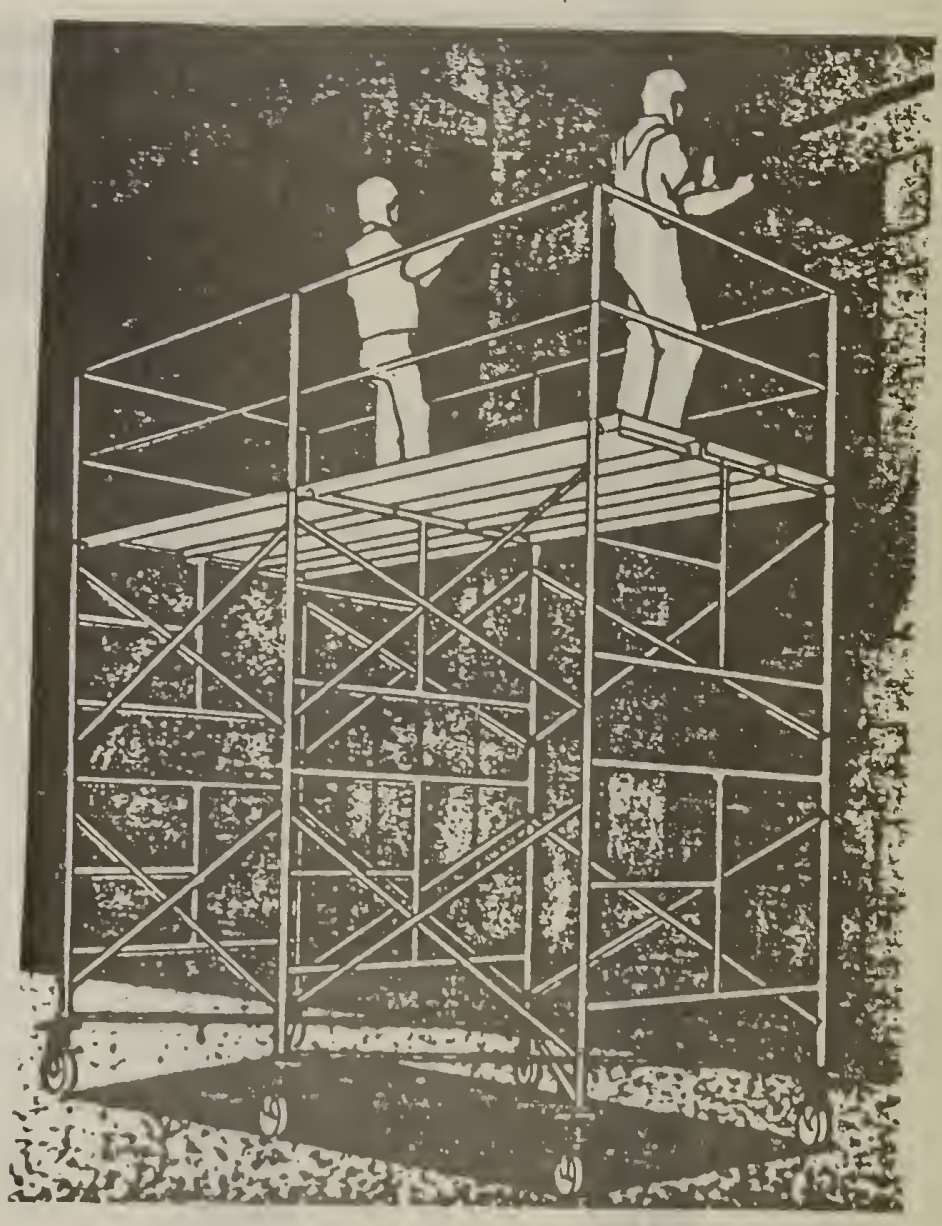

(b) Type 4

Figure A.6. Manually propelled mobile (a) ladder stand and (b) scaffold (tower). 

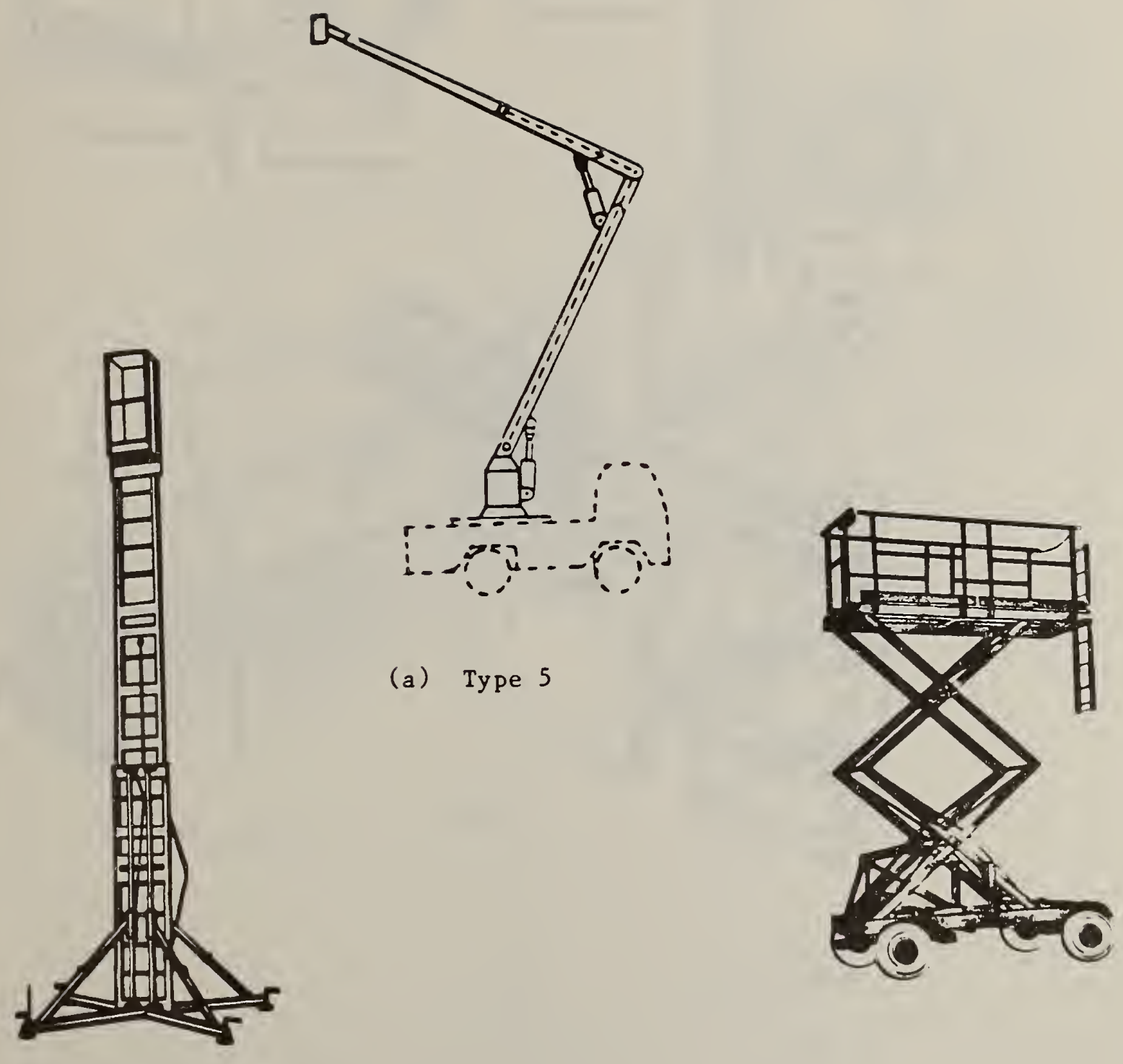

(b) Type 6

(c) Type 7

Figure A.7. (a) Vehicle-mounted elevating and rotating, (b) telescoping, and (c) self-propelled elevating work platforms. 


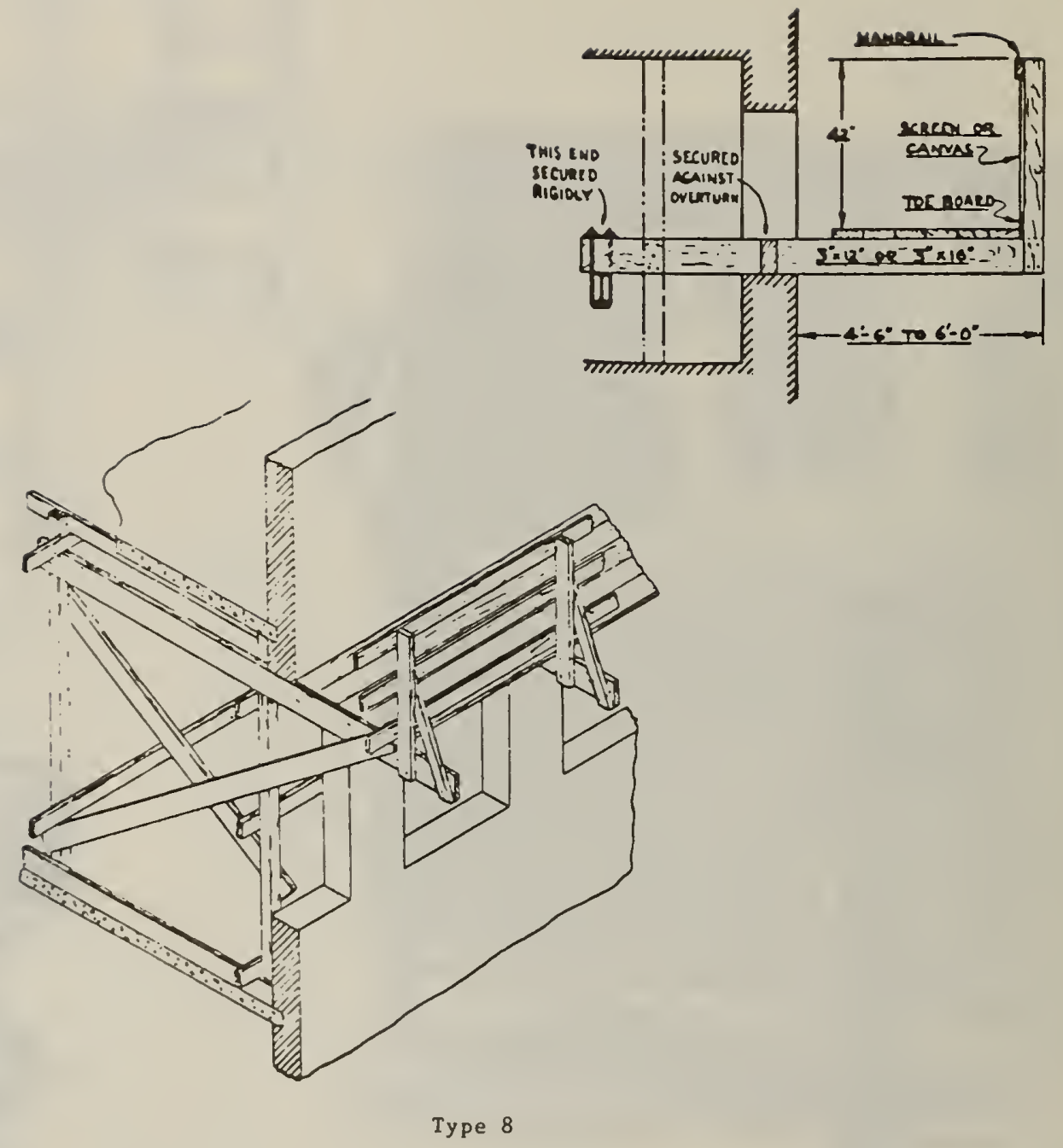

Figure A.8. Outrigger scaffold

$$
\text { A }-10
$$




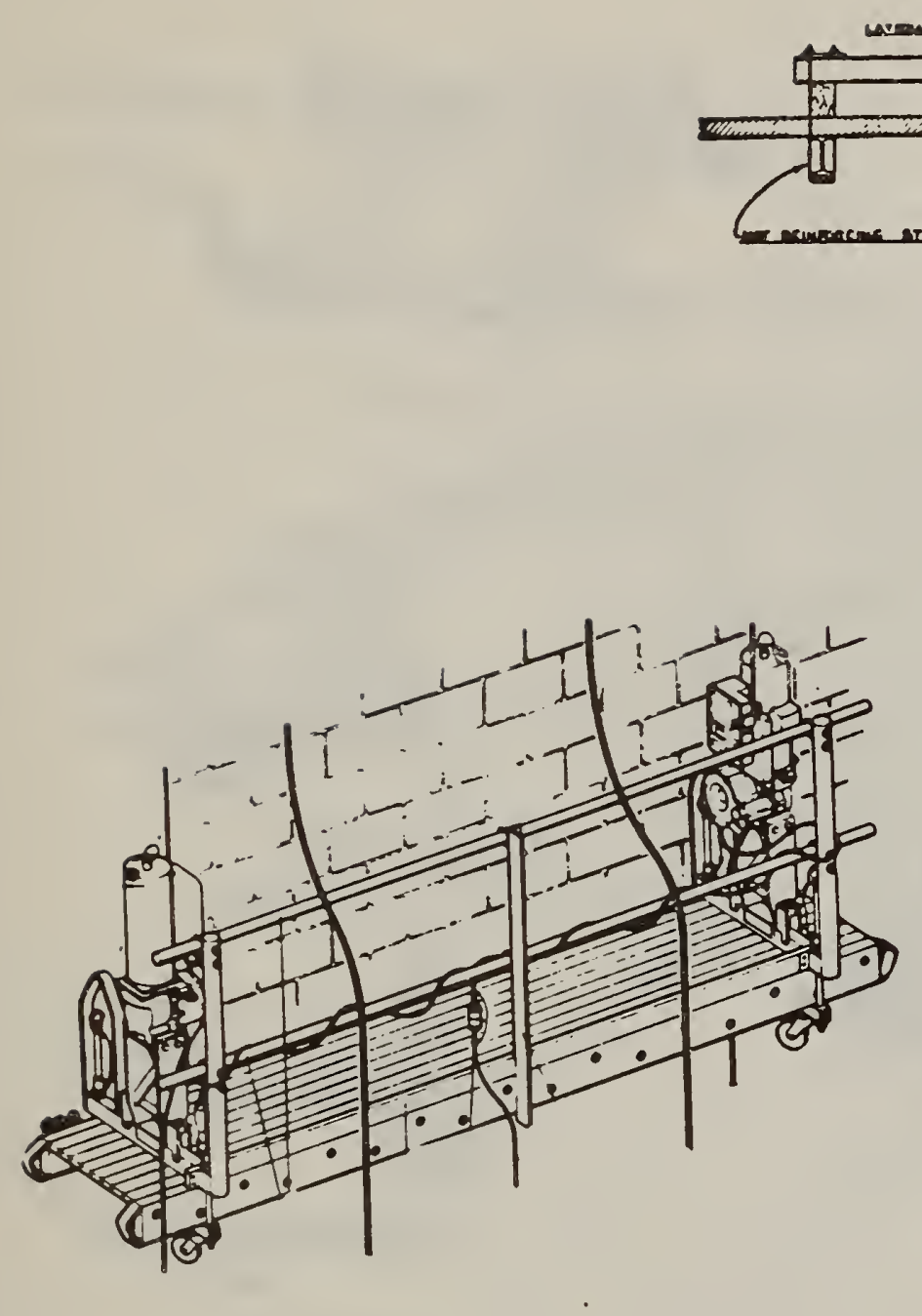

(b) Type 10

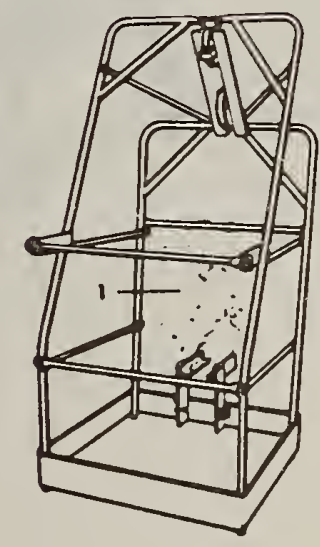

(c) Type 11

Figure A.9. (a) Adjustable multiple-point (masons' or stone-setters'), (b) twopoint (swinging), and (c) single-point suspension scaffolds. 

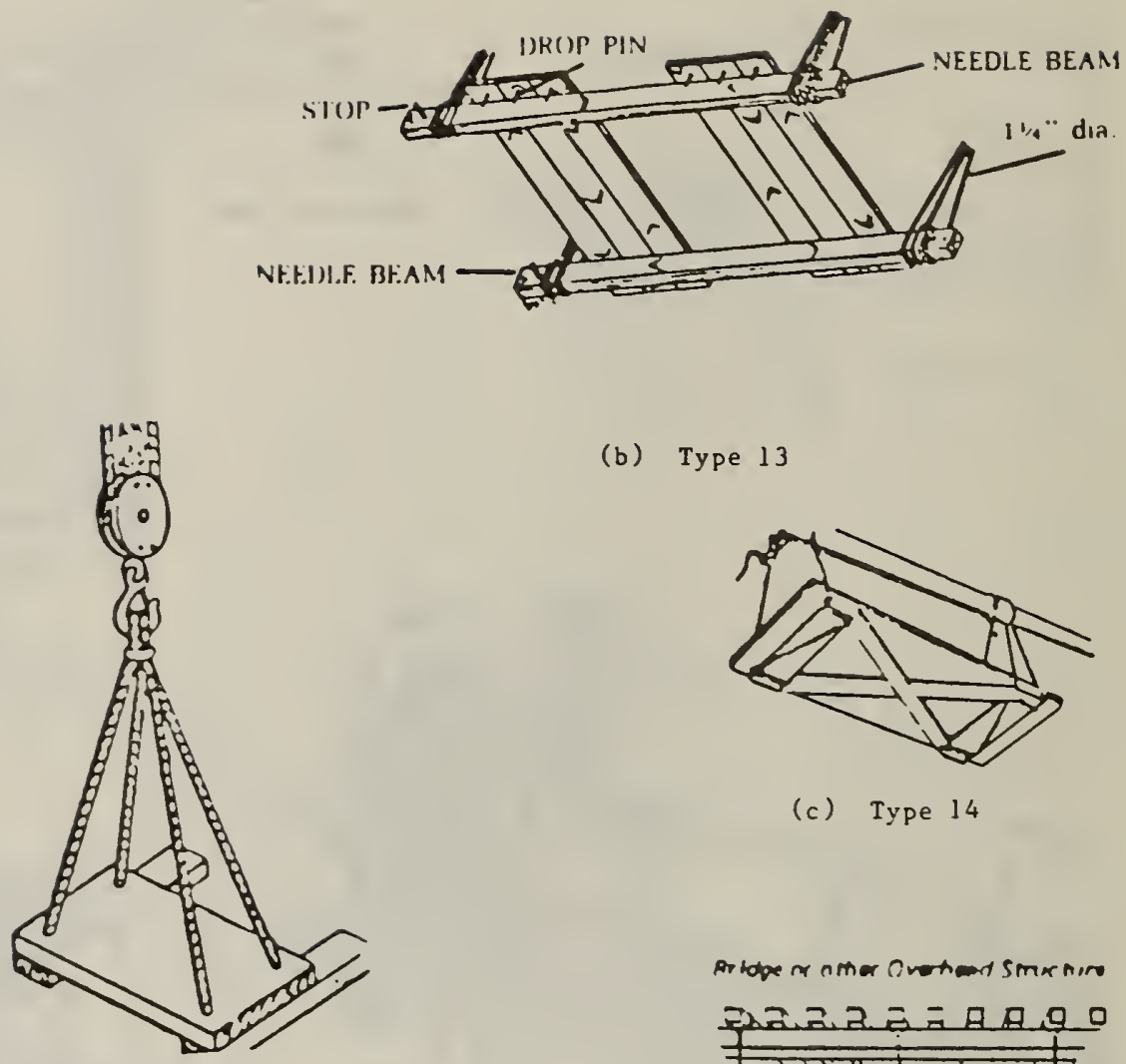

(b) Type 13

(a) Type 12

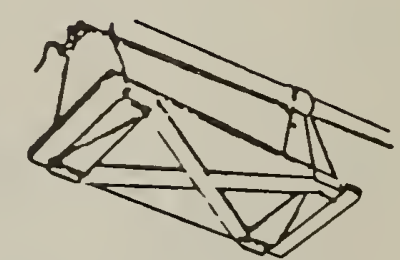

(c) Type 14

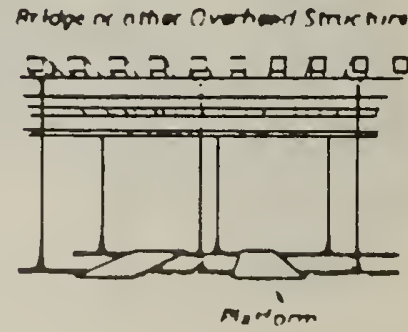

(d) Type 15

Eigure A.10. (a) Boatswain's chair, and (b) needle beams, (c) float or ship, and (d) catenary scaffolds.

$$
A-12
$$




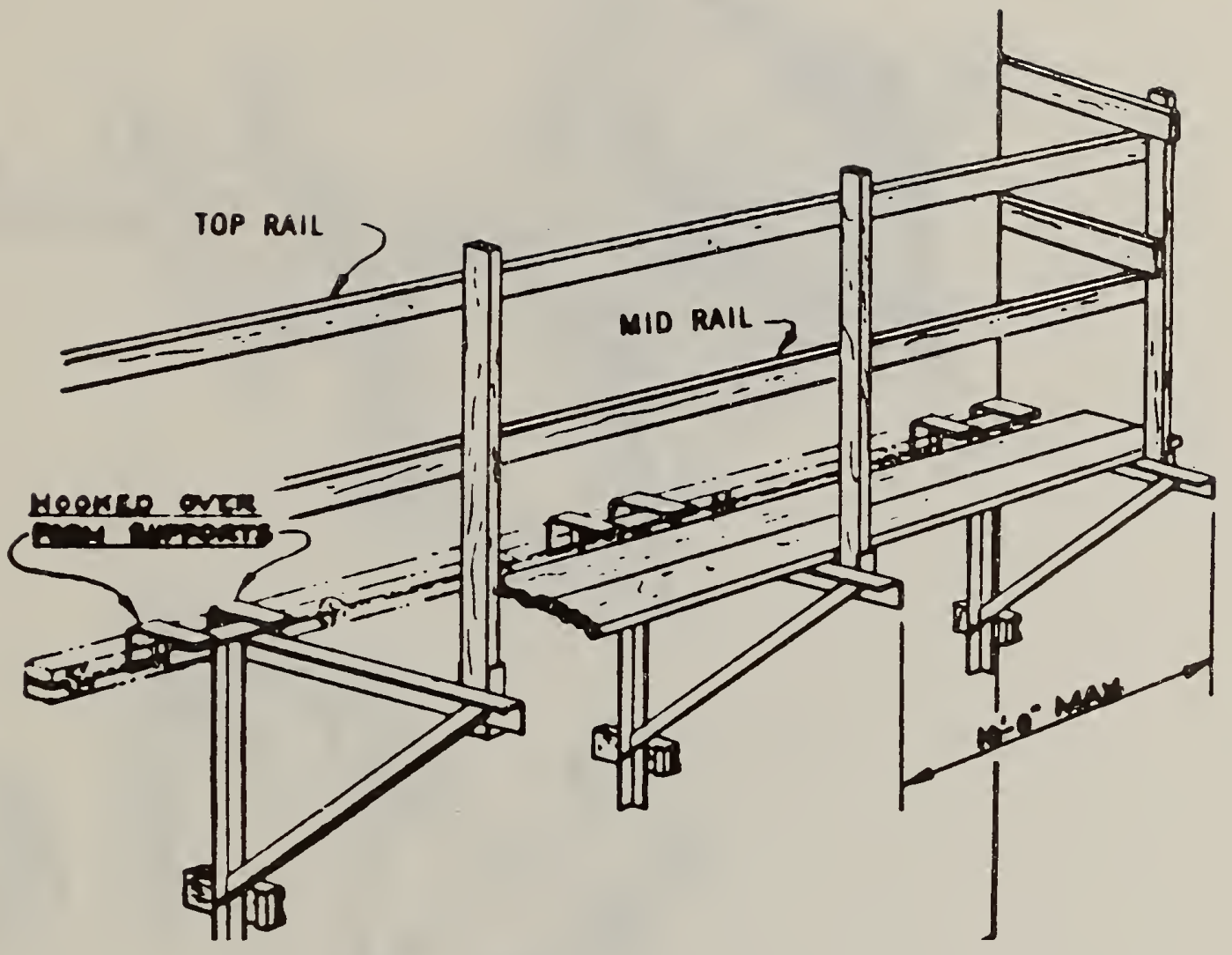

Type 16

Figure A.11. Bracket (carpenters' bracket) scaffold. 


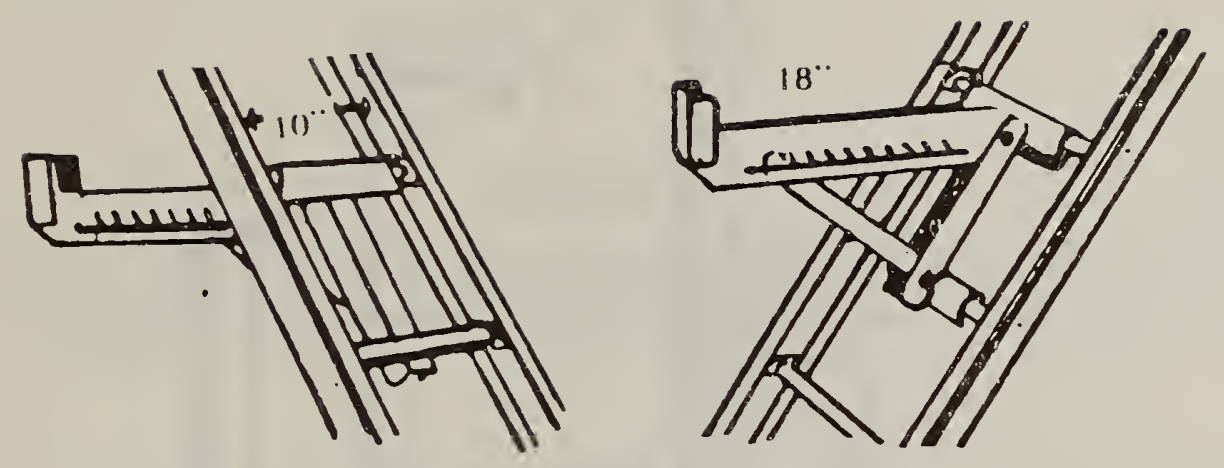

(a) Type 19

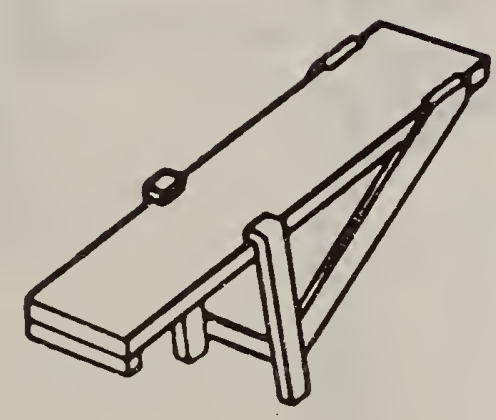

(b) Type 20

Figure A.13. (a) Ladder jack and (b) window jack scaffolds. A-15 


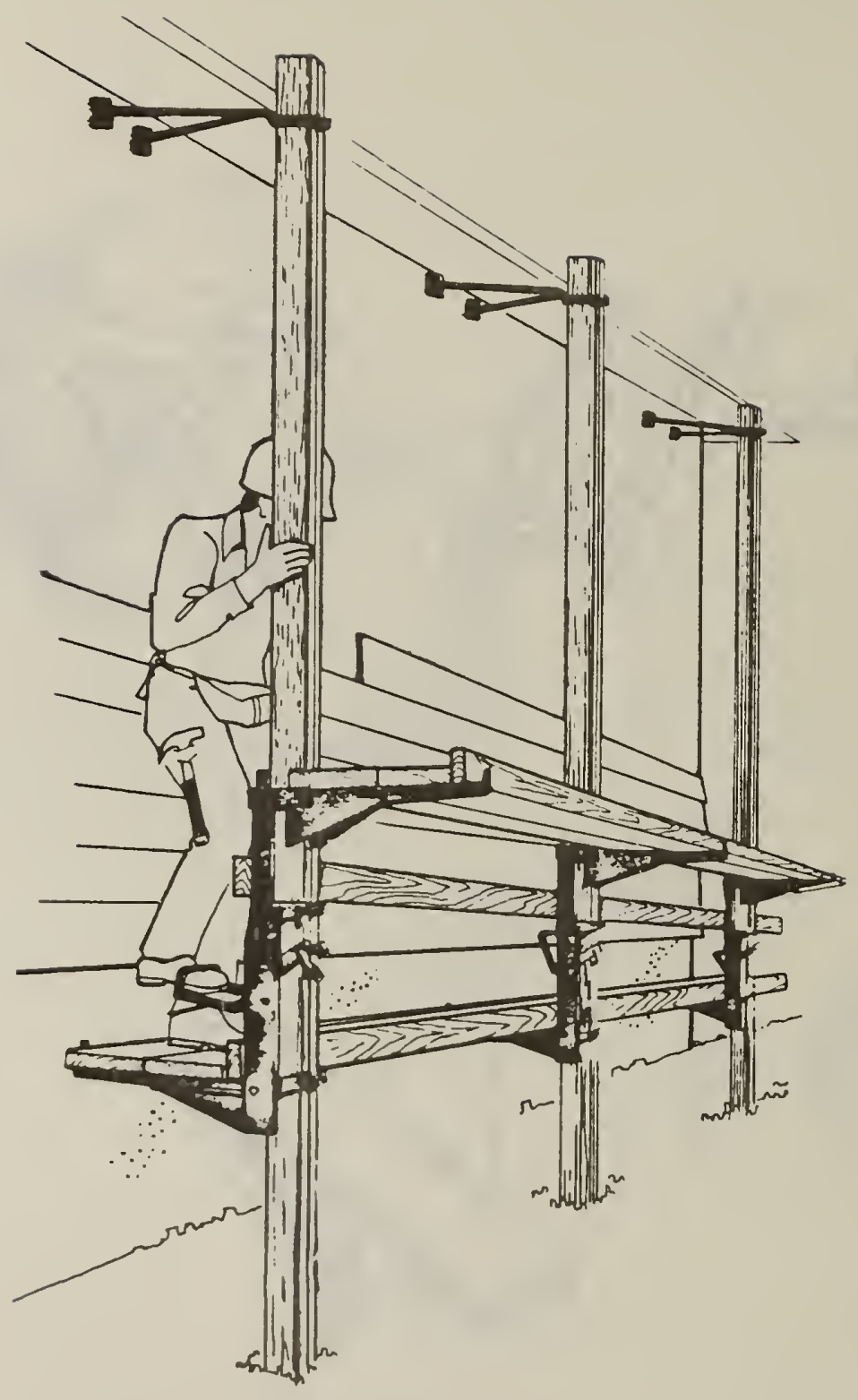

Type 21

Figure A.14. Pump jack scaffold.

$$
\text { A-16 }
$$


APPENDIX B

SUMMARY AND REVIEW OF EXISTING STANDARDS FOR THE DESIGN OF

SCAFFOLD WORK PLATFORMS CONSISTING OF WOOD PLANKING 


\section{INTRODUCTION}

This Appendix provides a summary and review of certain existing standards used in determining strength and design values for wood construction. These standards are listed below and are referred to throughout this section. The original formats have been maintained in order that clarity and cross-referencing might be facilitated.

The purpose of this section is to identify the technical bases by which wood design values are obtained and to convey, through the scaffolding provisions of ANSI and OSHA, the need to recognize these bases. In particular, the actual factor of safety determined by these technical bases is is different from that specified by the codes and standards for scaffolding. It is recommended that the reader become familiar with the following documents.

- ASTM: D245-74, Standard Methods for Establishing Structural Grades and Related Allowable Properties for Visually Graded Lumber.

- ANSI/ASTM: D2555-78, Standard Methods for Establishing Clear Wood Strength Values

- National Design Specification for Wood Construction; 1977.

\section{B.1 APPLICABLE PROVISIONS IN EXISTING STANDARDS}

\section{B.1.1 ANSI Al0.8-1974}

\section{General Requirements for All Scaffolds}

3.4 Scaffolds and their components shall be capable of supporting without failure at least four times the maximum intended load. (except)

3.9 All planking shall be 2-in (nominal) selected for scaffold plank use as recognized by grading rules approved by the Board of Review of the American Lumber Standards Committee for the species of wood used. $1 / *$ The maximum permissible spans for $2 \times 10$-in (nomina1) or $2 \times 9$-in (rough) planks shall be as shown in the following table.

\begin{tabular}{cccc}
\multicolumn{2}{c}{$\begin{array}{c}\text { Working Load } \\
\text { psf }\end{array}$} & \multicolumn{3}{c}{$\begin{array}{c}\text { Permissible Span } \\
\left.\text { (KN } / \mathrm{m}^{2}\right)\end{array}$} & & & (m) \\
\cline { 3 - 5 } 25 & $(1.2)$ & 10 & $(3.1)$ \\
50 & $(2.4)$ & 8 & $(2.4)$ \\
75 & $(3.7)$ & 7 & $(2.1)$
\end{tabular}

* Numerical superscripts designate notes listed at the end of this Appendix. 
The maximum permissible span for $1-1 / 4 \times 9$-in or wider plank of full thickness i: $4 \mathrm{ft}$ with medium loading of $501 \mathrm{~b} / \mathrm{ft}^{2}$. Fabricated planking may be used if designed in accordance with 3.4 of this section. (excerpt)

\section{B.1.2 ASTM D245-74}

\section{Foreword}

\subsection{Visual grading procedure:}

1. Examine all four faces and ends of piece.

2. Evaluate location, size, and nature of knots and other features appearing on the surfaces over the entire length.

3. Assign strength ratio for pieces representing strength in relation to strength without presence of weakening characteristics.

\subsection{Use classification of structural lumber}

The various factors affecting strength such as knots, deviations of grain, shakes, and checks, differ in their effect, depending on the kind of loading and stress to which the piece is subjected. Structural lumber is therefore often classified according to its size and use. (excerpt)

Classes: joists and planks, beams and stringers, posts and timbers, and structural boards.

Flanks - pieces of rectangular cross section, 2-4 in in least dimensions, graded primarily for strength in bending flatwise.

3.4 Essential elements of stress grade description:

1. Grade name identifying use class.

2. Permissible growth characteristics that affect mechanical properties.

3. Allowable properties for the grade related to its strength ratio.

6. Determination of Allowable Properties for Timber Design

6.1 1. Average wood property values and their standard deviation are obtained from Tables 1-3, ASTM D2555-78, for a particular species of wood.

2. Allowable properties for green lumber are computed according to the permitted growth characteristics. It is assumed that design loads act for a normal duration (taken to be $10 \mathrm{yr}$ ) and 
are realistic, and that each member carries its own load.

A 5 percent exclusion limit is assumed, that is, the allowable stresses are intended to be less than the stress permissible for 95 percent of the species in a species group and stress grade.

6.2 The 5 percent exclusion limit value for bending strength, et. al. obtained from ASTM D2555-78 when divided by an adjustment factor (given in Table 9) gives the allowable design properties for clear straight-grained wood. The factor includes an adjustment for normal load duration and a factor of safety.

6.4 The properties obtained in 6.2 are further modified according to the permitted characteristics in any stress grade by multiplying the properties by the appropriate strength factors. These factors include slope of grain, knot size and location, variation in lumber size, defects etc., and are cited in 4.2 and are highlighted below.

1. Grading factor - reduces the strength value in accordance with the growth characteristics (slope of grain, knots, shakes, checks, and splits) permissible for a particular grade. (Note unsound knots and limited amounts of decay in its early stages are permitted in some of the lower stress - rated grades used in light framing.)

2. Density factor - increases the strength value for the effect of specific gravity greater than the average value of the particular species. Density is in part determined by the rate of growth of a particular species (number of annual rings per radial strength).

3. Seasoning factor - increases strength value for effect of molsture content below that of green lumber. (Note - maximum moisture content expected in the field must be estimated by the designer.)

4. Temperature factor - increases or decreases the strength value for the effect of temperature substantially different from the laboratory temperature of $68 \pm 7 \mathrm{~F}(20 \pm 3 \mathrm{C})$ specified for the text. The effect of temperature depends on the moisture content, but generally increases strength during cooling and decreases strength during heating. (Note - the range and effect of temperature expected in the field must be estimated by the designer.)

5. Load duration factor - decreases the strength value for the effect of duration of load and stress different than the $5 \mathrm{~min}$ load duration specified for testing. (Note - grading procedures incorporate this assuming a normal duration of 10 years; the variation from the normal condition of the load duration expected in the field must be estimated by the designer and the effect ascertained from the appropriate curve or equation expressing the strength - load duration relation.) 
7. Modification of Allowable Properties for Design Use

Note 2 - The principal modifications made in design properties are summarized in Table 10. It is assumed to be the final responsibility of the designing engineer to relate design assumptions and allowable properties, and to make modifications of the allowable properties for seasoning and duration of load to fit a particular use. These modifications are often subject to the requirements of a building code. This section contains some recommended modification criteria. (excerpt)

\section{B.1.3 ASTM D2555-78}

Note 9 - An exclusion limit is a level of strength below which a selected percentage of the strength values are expected to fall and corresponds to a selected probability point from the frequency distribution of strength values. A 5 percent exclusion limit for a species or regional subdivision is obtained by multiplying the standard deviation for the strength property under consideration by $1.645^{2}$ and subtracting the product from the average strength values. (excerpt)

Al. Principals for Conversion to Working Stresses

A1.7 Factor of safety.

Working stress standards for marketed wood products should take into account, after applying the foregoing factors (duration of load, moisture content, temperature, strength reducing characteristics, and shape and form), whether a further reduction of stress for factor of safety should be made, and if so how much. The accounting should be made preferably by considering the factor of safety to be multivalued and as depending upon conditions of both strength and use. The factor of safety may recognize differences in the hazards and the consequences of failure appropriate to the expected uses of the various marketed wood products. An extended discussion of the factor of safety is found in ASCE Transactions, Paper No. 3051, "Factor of Safety in Design of Timber Structures," (1960). (excerpt)

\section{B.2 APPLICATION TO DESIGN OF WOOD WORK FLATFOKMS}

Structural design parameters:

1. Loads - depend on service type and the natural environment.

2. Species and section properties of planking - depend on availability.

3. Bending stress - depends on span, section properties, magnitude and distribution of loads, ard support conditions.

4. Factor of safety - ratio of expected strength to expected stress and its magnitude depends on uncertainties in the estimation of loads and resistance and on the consequences of failure. 
Application of code provisions by a design example:

1. Estimate working loads, w: 25,50 and 75 psf $\left(1.2,2.4\right.$ and $\left.3.7 \mathrm{kN} / \mathrm{m}^{2}\right)$

2. Select, for example, $2 \times 10$ in ( $51 \times 254 \mathrm{~mm}$ ) (nominal) eastern spruce.

3. Assume uniform load w acts over entire span, L, and that the planks are simply supported at their end. According to the technical theory of mechanics of solids the maximum bending stress, $f$, occurs at the extreme fibers (top and bottom of the section at midspan) and has magnitude computed as follows:

$$
f=\frac{3}{4} w(L / h)^{2}
$$

where $w=$ load per unit of platform area

$\mathrm{L} / \mathrm{h}=$ span to thickness ratio of planking

Typically, the designer selects appropriate values for the above listed parameters in accordance with code provisions. ANSI A10.8 provision 3.4 (which is adopted by OSHA and several other authorities with enforcement powers) presents an overriding strength requirement of 4 times the intended load. Maximum spans for planks subject to various loading levels are then prescribed in provision 3.9. Provision 3.4 can be interpreted to mean that a factor of four should be applied to the maximum intended working load thus generating an ultimate design stress. Applying Equation B.I and using the span permitted for this working load, the designer would compute the bending stress below which failure should not occur. The prescribed level of safety would presumably be assured by selecting a grade of wood with a modulus of rupture higher than the computed value. However, if this method is used in obtaining a final factored ultimate stress, it is not consistent with the National Design Specification for Wood Construction (NDSWC) procedure used in establishing the allowable design stress for wood construction as will now be demonstrated.

Table 4A of the supplement to the (NDSWC) gives allowable bending stresses derived using the procedure outlined in ASTM D245-74. Review of these procedures reveals that the allowable values trace back to an average modulus of rupture for a clear-grained, green specimen $1.25 \times 1.25 \times 48$ in $(32 \times 32 \times 1219 \mathrm{~mm})$ tested in the laboratory. As was mentioned above, these values must be modified to incorporate variation in the properties of wood. To illustrate the complexity concerning the varying factor of safety arising when applying the provisions of NDSWC, the following example will be considered.

Selecting an eastern spruce which according the Agriculture Handbook No. 71 (USDA), dries easily and is stable after drying, is moderately light in welght and easily worked, has moderate shrinkage, and is moderately strong, stiff, tough, and hard... The largest use of eastern spruce is in plywood. It is also used for framing material, general millwork, boxes and crates, 
ladder rails, scaffold planks, and piano sounding boards." (Note - No. 1 eastern spruce is specified by the National Research Council of Canada (NRCC) to be a minimum standard grade for lumber used in the construction of scaffolds.)

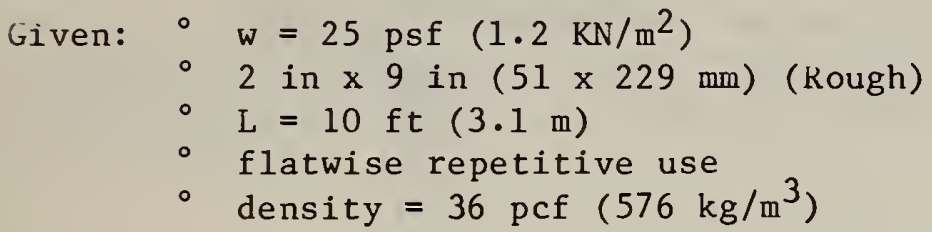

The allowable bending stress for No. 1 grade eastern spruce $2 \times 9$ in planking when there are repetitive members is 1250 psi. This value is increased by a factor of 1.22 for the case of flatwise bending, thus the allowable stress is 1525 psi. This represents the allowable stress for wood used at a maximum moisture content of $19 \%$ and under a 10 year 1 oad duration. To calculate the expected ultimate of this wood, the procedures of ASTM D-245 may be used:

$$
\mathrm{f}_{\mathrm{a}}=\frac{\mathrm{f}_{\mathrm{u}}^{\prime}}{\mathrm{k}}
$$

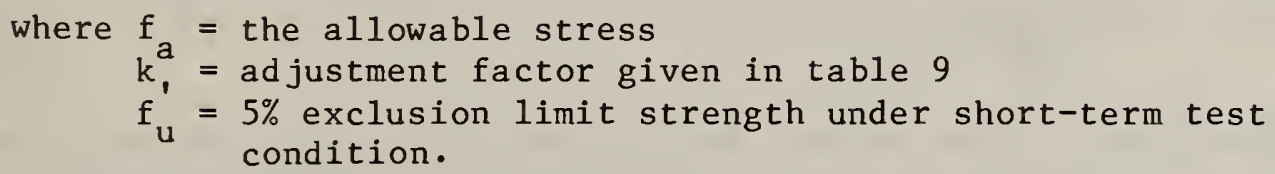

For the case of bending the adjustment factor is 2.1 ; this value is derived as the product of a load duration factor and a partial safety factor. The load duration factor is used to convert the short-term strength from laboratory tests to strength under sustained load. For a 10-year load duration the load reduction factor is estimated to be 0.625 (using Figure 5 of ASTM D245). Thus, according to B.2, the short-term ultimate strength would be $(1525)(2.1)=3200$ psi, and the ultimate strength under 10-year load duration would be $(3200)(0.625)=2000$ psi.

The parameter of major interest is the actual factor of safety which exists for a given situation. This actual factor of safety is defined by the following ratio;

$$
\text { F.S. = (ultimate strength)/(actual stress). }
$$

The actual stress can be calculated for the given problem by equation B.1. Using the prescribed span, loads and board dimensions, the actual stress is found to be;

$$
\mathrm{f}_{\text {act }}=580 \mathrm{psi}\left(4 \mathrm{~N} / \mathrm{mm}^{2}\right)
$$


The ultimate strength (that is, 5\% exclusion limit) for the No. 1 grade eastern spruce planking would be 2000 psi if the moisture content does not exceed $19 \%$ and the load duration is assumed to be 10 years. The provisions of NDSWC specify a strength reduction factor of 0.86 in cases where moisture content exceeds $19 \%$. In addition, there are modification factors for load duration other than 10 years as follows:

load duration

$$
\begin{aligned}
& >10 \text { years } \\
& \leq \quad 2 \text { months } \\
& \leq \quad 7 \text { days } \\
& \text { wind or earthquake } \\
& \text { impact }
\end{aligned}
$$

\section{modification factor}

$$
\begin{aligned}
& 0.90 \\
& 1.15 \\
& 1.25 \\
& 1.33 \\
& 2.0
\end{aligned}
$$

The ultimate strength in this problem will depend on moisture content and load duration and thus the computed safety factor can have one of many values. To illustrate the possible range, the upper and lower bounds of the actual factor of safety are computed as follows:

\section{Upper bound:}

Impact loading, less than $19 \%$ moisture content.

Ultimate strength $=2000 \times 2 \times 1=4000$ psi

$$
\text { F.S. }=\frac{4000}{580}=6.9
$$

Lower bound

Greater than 10 year loading, more than $19 \%$ moisture content.

Ultimate strength $=2000 \times 0.9 \times 0.86=1550 \mathrm{psi}$

$$
\mathrm{F} \cdot \mathrm{S} \cdot=\frac{1550}{580}=2.7
$$

Of these two limits, the upper is unlikely in that it assumes that the entire design load is due to impact. It would seem reasonable to use a 10 -year load duration and molsture content above $19 \%$ for routine scaffolding application. Under these conditions the safety factor would be:

$$
\text { F.S. }=\frac{2000 \times 1 \times 0.86}{580}=3.0
$$

The above has illustrated a serious inconsistency in scaffolding standards modeled after ANSI A10.8. Using the prescribed design loads and maximum spans can lead to a factor of safety less than the overriding prescribed value of 4 .

The complex and technical procedures by which wood design values are obtained are due to the anisotropic and variable nature of wood; that 1s, wood has properties that vary with orientation of the wood relative 
to the applied loads and these properties are altered by natural and manufacturing defects. Consequently, the general provision of ANSI and OSHA, which specifies a 4 to 1 strength factor reflects incognizance regarding the existing technical bases by which wood design values are determined.

Therefore, technical research addressing strength and safety requirements must be performed in order that a more meaningful safety factor can be identified per scaffolding type and bo incorporated in the codes and standards.

\section{Notes}

1 Grading rules are promulgated by associations of manufacturers and approved by the Board of Review of the American Lumber Standards Committee, the National Grading Rule Committee, and the National Bureau of Standards. The National Design Specification for Wood Construction (NDSWC), 1977, presents allowable strength values for various species based on the rules set forth by seven agencies having jurisdiction in different parts of the United States and Canada. The design values for visually graded lumber are based on the provisions of ASTM D245-74, "Methods for Establishing Structural Grades and Related Allowable Properties for Visually Graded Lumber." These values are published in Table $4 \mathrm{~A}$ of this supplement to (NDSWC) (1977).

2 The value of 1.645 is derived from an assumed normal (bel1-shaped) probability distribution function. 


\begin{tabular}{|c|c|c|}
\hline $\begin{array}{c}\text { U.S. DEPT. OF COMM. } \\
\text { BIBLIOGRAPHIC DATA } \\
\text { SHEET }\end{array}$ & 1. PUBLICATION OR REPORT NO. \\
\hline NBSIR & $79-1937$ \\
\hline
\end{tabular}

4. TITLE AND SUBTITLE

5. Publication Date

APRIL 1980

Review of Current Codes and Standards for Scaffolds

7. AUTHOR(S) S. George Fattal, Christopher Mullin, Hai S. Lew, Bernard J. Hunt

9. PERFORMING ORGANIZATION NAME AND ADDRESS

NATIONAL BUREAU OF STANDARDS

DEPARTMENT OF COMMERCE

WASHINGTON, DC 20234

12. SPONSORING ORGANIZATION NAME AND COMPLETE ADDRESS (Stroot, City, Stato, zIP)

National Institute of Occupational Safety and Health

Department of Health, Education and Welfare

Washington, D.C.

15. SUPPLEMENTARY NOTES

Document describes a computer program; SF-185, FIPS Software Summary, is attached.

16. ABSTRACT (A 200-word or ioss factual summary of most signilficant information. If documerit includes a significant bibilography or Hlerature aurvey, montion it hore.)

This report presents a critical review of the provisions in existing codes and standards for the design, erection, operation and maintenance of scaffolds used in construction work and other applications. The requirements in these documents were examined from the standpoint of clarity, consistency and completeness. Ambiguities arising from conflicting requirements or from provisions that led to more than one interpretation, and lack of consideration of major safety-related structural, environmental and human factors are highlighted. In addition, the adequacy of, and the rationale behind, the prescribed provisions are examined. These are supplemented by a specific application appearing in Appendix B. Appendix A illustrates common types of scaffolding systems that have been addressed by at least one of the codes or standards examined. The findings of this study serve to identify principal areas of needed research to improve present scaffolding practices.

17. KEY WOROS (oix to twolve ontrles; alphebeticai order; capitallze onil the firet ietter of the firat koy word unieas a proper name; - eparated by cemicotone)

Codes and standards; construction safety; design; loads; maintenance; occupational hazards; scaffolds; stiffness; strength; structural safety; work surfaces.

18. AVAILABILITY

- Unllmited

For Official Distrlbution. Do llot Reiease to NTIS

Order From Sup. of DoC. U.S. Government Printing Office, Washington, DC 20402, SD Stock No. SNO03-003-

[X] Order From National Technical Information Service (NTIS), Springfield, VA. 22161

\begin{tabular}{|l|c|}
\hline $\begin{array}{l}\text { 19. SECURITY CLASS } \\
\text { (THIS REPORT) }\end{array}$ & $\begin{array}{c}\text { 21. NO. OF } \\
\text { PRINTED PAGES } \\
\text { UNCLASSIFIED }\end{array}$ \\
\hline $\begin{array}{l}\text { 20. SECURITY CLASS } \\
\text { (THIS PAGE) }\end{array}$ & 69 \\
UNCLASSIFIED & 22. Price \\
\hline
\end{tabular}



